\title{
On-the-Job Search and Labor Market Reallocation
}

\author{
Murat Tasci* \\ University of Texas at Austin \\ Department of Economics
}

February 13, 2006

\begin{abstract}
This paper studies amplification of productivity shocks in labor markets through on-thejob-search. There is incomplete information about the quality of the employee-firm match which provides persistence in employment relationships and the rationale for on-the-job search. Amplification arises because productivity changes not only affect firms' probability of contacting unemployed workers but also of contacting already employed workers. Since higher productivity raises the value of all matches, even low quality matches become productive enough to survive in expansions. Therefore the measure of workers in low quality matches is greater when productivity is high, implying a higher probability of switching to another match. In other words, firms are more likely to meet employed workers in expansions and those they meet are more likely to accept firm's job offer because they are more likely to be employed in a low quality match. This introduces strongly procyclical labor market reallocation through procyclical job-to-job transitions. Simulations with a productivity process that is consistent with average labor productivity in the U.S. show that standard deviations for unemployment, vacancies and market tightness (vacancy-unemployment ratio) match the U.S. data. The model also reconciles the presence of endogenous separation with the negative correlation of unemployment and vacancies over business cycle frequencies (i.e. it is consistent with the Beveridge curve).
\end{abstract}

Keywords: On-the-Job Search; Amplification; Business Cycles; Job-to-Job Flows

JEL classification: E24, E32, J40, J41, J64.

${ }^{*}$ Department of Economics, University of Texas at Austin, 1 University Station C3100, Austin, TX 78712. E-mail: mtasci@eco.utexas.edu. I am indebted to Dean Corbae for his guidance. I am grateful to Russell Cooper, Burhanettin Kuruscu, Robert Shimer and seminar participants at the University of Texas at Austin for helpful comments in the early stages of research on this paper. I wish to thank seminar participants at Penn State, USC Marshall School of Business, Cleveland FED and University of California, Riverside. All errors are mine. 


\section{Introduction}

In the last two decades, labor market search models have been used extensively to understand aggregate labor market phenomena, such as equilibrium unemployment and vacancies (Mortensen and Pissarides (1994), Pissarides (2000)). This theoretical framework also proved to be useful in analyzing the effects of various labor market policies including unemployment insurance and labor turnover costs. However, search models have recently been criticized for their business cycle implications. In particular, Shimer (2005a) and Hall (2005) argue that standard models of labor market search require implausibly large shocks to generate substantial variation in key variables; unemployment, vacancies and market tightness (vacancy to unemployment ratio) ${ }^{1}$. Standard deviations of unemployment and vacancies are 10 times, market tightness is 19 times as large as the standard deviation of the average product per worker in the U.S. A puzzle arises since a standard calibration of Mortensen-Pissarides model implies that the variations in all these variables is basically the same as productivity.

This paper studies amplification of productivity shocks in labor markets through on-thejob-search. Nagypal (2004a) and Shimer (2005b) argue that job-to-job transitions are crucial for the cyclical worker reallocation. Exploiting dependent interviewing methods introduced in the CPS in 1994, Fallick and Fleischman (2004) find that these flows are large: On average $2.6 \%$ of employed workers change employers each month. Moreover, job-to-job transitions turn out to be significantly procyclical. This particular flow cannot be analyzed by standard search models. Thus, on-the-job search seems to be a natural extension of the standard labor market search model.

In the model, workers are allowed to search for another job while employed without incurring any cost. There is also symmetric incomplete information about the quality of the match, which provides persistent employment relationships and a rationale for on-the-job search. Thus, workers in low quality matches have an incentive to search for and accept better quality matches. In equilibrium, workers are distributed over different match qualities at any point in time. Am-

\footnotetext{
${ }^{1}$ Fujita and Ramey (2005) present simulations of the 'standard' Mortensen - Pissarides model that show much more variability. However, their representation of the Mortensen - Pissarides model deviates from the standard version in many respects, including a different timing assumption and different separation rates for new and prevailing matches.
} 
plification arises in the model because productivity changes not only affect firms' probability of contacting unemployed workers but also of contacting already employed workers. For instance, in expansions, firms are more likely to meet employed workers and those they meet are more likely to accept firm's job offer because they are more likely to be employed in a low quality match. This provides the incentive for the firms to post more vacancies than predicted in the standard model. The logic behind this is simple; since higher productivity raises the value of all matches, even low quality matches become productive enough to survive in expansions. Therefore the measure of workers in low quality matches is greater when productivity is high, implying a higher probability of switching to another match. This introduces strongly procyclical labor market reallocation through procyclical job-to-job transitions. Therefore, the effects of productivity shocks on employment distribution play a key role in generating the desired amplification.

One other contribution of on-the-job search that helps to create amplification is the presence of larger stock of job seekers. In the standard labor market search model, a positive productivity shock leads to higher number of vacancies and lower unemployment by increasing the job finding rate. As the productivity shock persists, since all new workers come from the unemployment pool, firms will expect to find increasingly less number of unemployed workers to fill in the available vacancies. This dampens the positive effect of productivity shock on the supply of vacancies. With on-the-job search, however, this offsetting effect will not be present. To the contrary, due to a substantial number of employed workers at low quality matches who are ready to switch, firms have incentives to post additional vacancies.

The model provides a possible channel for amplification that does not require changing the wage determination process or the information structure to a large extent. In particular, simulations show that the standard deviations for all three labor market variables are matched. The model also successfully predicts that market tightness, defined as the ratio of vacancies to unemployment, is more volatile than both vacancies and unemployment. In addition, the presence of endogenous separation is reconciled with the negative correlation between unemployment and vacancies over business cycle frequencies.

This paper also has a computational contribution. On-the-job search with match het- 
erogeneity implies that the entire employment distribution becomes a state variable for the recursive problem. It is well known in the literature that this complicates the numerical solution of the equilibrium. I utilize the algorithm used by Krusell and Smith (1998) to address a similar problem. The computational exercise suggests that approximating the worker's acceptance probability of a firm's job offer suffices to characterize the equilibrium. This enables me to numerically solve for the stochastic equilibrium of this economy. In contrast, other studies that modeled on-the-job search either used some simplifying assumptions to get rid of the endogenous effects of heterogeneity or simply restricted the analysis to non-stochastic equilibrium.

The next section discusses the related literature. Section 3 describes the U.S. aggregate labor market data. It shows that the variation in average labor productivity is much less than the observed variation in vacancies, unemployment and market tightness. This section also includes some results from a simulation of the standard labor market search model in order to quantify the size of the "amplification puzzle". Section 4 describes the economic environment and lays out the dynamic optimization problem of agents. Section 5 characterizes the equilibrium of the economy and describes the computational procedure to handle the presence of the employment distribution in the state space. Section 6 and Section 7 discuss calibration and the solution to the computational problem in detail respectively. Section 8 presents the results from the simulation of the model and discusses the implications of the model.

\section{Related Literature}

Early studies of labor market search either failed to address the magnitude of the exogenous forcing process (Mortensen and Pissarides (1994), Cole and Rogerson (1999)) or implied counterfactually positive relationship between unemployment and vacancies (Andolfatto (1996), Merz (1995), Ramey and Watson (1997)).

Shimer (2005a) and Hall (2005) claim that the reason for the lack of amplification in these models is the underlying wage determination mechanism. In search models, an increase in labor productivity raises the labor demand, hence the number of vacancies posted by firms. 
Since labor markets match vacancies and unemployment as an increasing function of both, more vacancies increase the job-finding probability of workers. Higher job-finding probability reduces unemployment, implying a negative relationship between vacancies and unemployment. However, since workers are now hired at a higher pace, unemployment duration also falls in addition to unemployment. This raises the workers' threat point in bargaining and leads to an offsetting change in terms of higher wages. Therefore, firms' incentive to create vacancies falls (Shimer (2005a), p. 25-26). Hall (2004, 2005), Shimer (2004) and Kennan (2004) build on this presumption and introduce wage rigidity either exogenously or through an endogenous mechanism. As I argue in this paper, a modification to the wage mechanism is not a necessary condition for amplification. Indeed, a recent paper by Mortensen and Nagypal (2005) discusses this point extensively, suggesting that wage rigidity per se is not the answer for amplification. For instance, assuming no bargaining strength for workers leads to constant wages that are equal to the reservation wage (i.e. the value of leisure). Even in this case, the variability of labor market variables relative to productivity are an order of magnitude smaller (Mortensen and Nagypal (2005), p.9).

Several recent studies also aim to provide a mechanism to amplify the effects of business cycle shocks on unemployment and vacancies (Hagedorn and Manovskii (2005), Krause and Lubik (2004), Nagypal (2005) and Silva and Toledo (2005)). Hagedorn and Manovskii (2005) use an unrealistically high value of leisure to generate amplification. Silva and Toledo (2005)'s result depends on a combination of right parameter values for separation, hiring and training costs. Krause and Lubik (2004) and Nagypal (2005) are closer to this paper in that both model on-the job search. In general on-the-job search introduces the heterogeneity of job seekers into the picture. Coupled with the aggregate uncertainty, this complicates the problem to a great extent. This might be the reason why Krause and Lubik (2004) assumes a segregated market for different kind of jobs to simplify the potential complexity of the model, whereas Nagypal (2005) only restricts the analysis to non-stochastic equilibrium. In contrast, I handle the heterogeneity that is induced through on-the-job search so that the stochastic equilibrium of the model could be studied. 


\section{U.S. Labor Market Facts}

This section presents some of the salient features of the U.S. aggregate labor market data over the business cycle to motivate the questions addressed in the paper. I focus on three key labor market variables; unemployment, vacancies and market tightness as defined by the ratio of vacancies to unemployment. These are standard variables describing the state of the labor market. Since the mechanism emphasized in this paper also has implications for transitions between different labor market states, I present two series that proxy transition probabilities between unemployment and employment. These measures are recently constructed by Shimer (2005a and 2005b).

Unemployment is the quarterly average of seasonally adjusted monthly data constructed by the Bureau of Labor Statistics (BLS) using the Current Population Survey (CPS) data. Vacancies are proxied by quarterly averages of the seasonally adjusted monthly Help-Wanted Advertising Index constructed by the Conference Board. The index is normalized to 100 for 1987. Market tightness variable is constructed using these two and equals the ratio of unemployment to vacancies. In order to determine productivity changes over the cycle, I use real output per person in the non-farm business sector. This particular series is chosen to ensure comparability with the recent body of literature. It is also a natural way to think about productivity in the standard Mortensen-Pissarides model. This series is part of BLS's Major Sector Productivity and Costs program. It is normalized to 100 for 1992.

Job finding and separation probabilities describe the hazard of changing labor market state. For instance, job finding probability is the hazard rate for an unemployed worker of finding a job. Hence, it gives the probability of switching between state of unemployment $(u)$ to state of employment $(e)$. The opposite of this measure is separation probability ( $e-u$ transition). Shimer uses short term unemployment data and total unemployment data to pin down these probabilities $^{2}$. Let $U_{t}$ be the number of unemployed in month $t, U_{t}^{s}$ be the number of workers unemployed less than a month in month $t$, and $E_{t}$ be the number of workers employed in month t. Then, job finding and separation probabilities are constructed by the following two formulas

\footnotetext{
${ }^{2}$ A detailed discussion of how these are constructed is in Shimer (2005a and 2005b). Data is available through his website: http://home.uchicago.edu/〜 shimer/data/
} 
respectively.

$$
\begin{gathered}
f_{t}=1-\frac{U_{t+1}-U_{t+1}^{s}}{U_{t}} \\
s_{t}=\frac{U_{t+1}^{s}}{E_{t}\left(1-f_{t} / 2\right)}
\end{gathered}
$$

The separation probability takes into account the possibility of having a short spell of employment in a month to get rid of the time aggregation bias. All of the data reported here are expressed as quarterly averages of monthly data, except the average labor productivity, which is quarterly. The data covers the post-war period, starting from first quarter of 1951 and ending by the end of 2003. All variables are expressed in log deviations from an HP filter with a smoothing parameter $10^{\wedge} 5$.

First, consider the cyclical variation in unemployment and vacancies relative to the labor productivity. As Figures 1 and 2 show, both variables show much more variability than the average labor productivity. Same is true for the cyclical variation of market tightness (see Figure 3) . The latter two variables show strong procyclicality as opposed to countercyclical unemployment. Figures (5) and (6) complement this picture. It appears from these two figures that job finding probability is strongly procyclical and separation probability is countercyclical. These findings are summarized in Table 1. The second row denotes the variables of interest: $u$ for unemployment, $v$ for vacancies, $v / u$ for market tightness, $u$-e for job finding probability, $e-u$ for separation probability and $z$ for labor productivity. The third row in the table states standard deviations of these variables and the fourth row gives one period auto correlations. Amplification of productivity shocks is clear from the third row. Both unemployment and vacancies are 10 times more volatile than labor productivity. Market tightness is even more volatile, approximately 19 times more. The amplification puzzle, which motivates this paper, states that the standard labor market search model cannot generate this much amplification based on a productivity process that resembles $z$ in the data. In order to compare data findings in Table 1 with the implications of the model, I simulate a standard Mortensen-Pissarides model. Since, this model is well known in the literature, details of it is presented in the Appendix (see 
Pissarides (2000) for an extensive treatment of the model and its implications).

\begin{tabular}{lllllll}
\hline \hline Table 1: & U.S. & DATA & \multicolumn{5}{c}{ (Quarterly, 1951Q1-2003Q4) } \\
\hline \hline Std & 0.19 & 0.20 & 0.38 & 0.12 & 0.07 & 0.02 \\
Auto & 0.94 & 0.95 & 0.95 & 0.91 & 0.73 & 0.89 \\
Cross & Correlations & & & & \\
\hline$u$ & & -0.89 & -0.97 & -0.95 & 0.71 & -0.42 \\
$v$ & & & 0.97 & 0.90 & -0.69 & 0.37 \\
$v / u$ & & & 0.95 & -0.72 & 0.40 \\
u-e & & & & -0.58 & 0.41 \\
$e-u$ & & & & & -0.52 \\
\hline
\end{tabular}

Table 2 presents simulation results from the standard Mortensen-Pissarides model. Productivity process is calibrated to match the actual $z$ series in terms of standard deviation and autocorrelation. In particular, I use a two point Markov process approximated to match the underlying AR(1) process of $z$ according to Tauchen's method (Tauchen, 1986). As Table 2 clearly indicates, the standard model implies almost the same magnitude of variation in all key variables. There is virtually no amplification. Third rows of Table 1 and Table 2 make this point clear beyond doubt. This discrepancy between the model's implications and the data is referred to as amplification puzzle in this paper. 


\begin{tabular}{|c|c|c|c|c|c|c|}
\hline \multicolumn{7}{|c|}{ Table 2: MP Model with Constant Separation } \\
\hline & $u$ & $v$ & $v / u$ & $\mathrm{u}-\mathrm{e}$ & $e-u$ & $z$ \\
\hline Std & 0.01 & 0.02 & 0.03 & 0.01 & 0 & 0.02 \\
\hline Auto & 0.85 & 0.74 & 0.81 & 0.81 & 1 & 0.81 \\
\hline \multicolumn{7}{|c|}{ Cross Correlations } \\
\hline$u$ & & -0.87 & -0.94 & -0.99 & 0 & -0.94 \\
\hline$v$ & & & 0.99 & 0.92 & 0 & 0.99 \\
\hline$v / u$ & & & & 1 & 0 & 1 \\
\hline $\mathrm{u}-\mathrm{e}$ & & & & & 0 & 1 \\
\hline$e-u$ & & & & & & 0 \\
\hline
\end{tabular}

One key feature of the data is that separations show a countercyclical variation. This is clearly evident in Figure 6 and Table 1. The standard model, however, assumes constant separations. Studies trying to model endogenous separations as a potential channel to introduce variations in unemployment provides a natural extension to the standard model. However, as argued in the introduction, endogenous separations usually lead to counterfactually positive correlation between unemployment and vacancies.

The negative relationship between unemployment and vacancies has long been recognized by researchers. Indeed, one of the key facts that the standard model was intended to explain was this negative correlation, which has been traditionally named as the Beveridge Curve. The U.S. Beveridge Curve is shown in Figure 4. This relationship is also apparent in Table 1 in the form of a strong negative correlation of -0.89 .

Shimer (2005a) provides a detailed discussion of why separation shocks alone, or separations in general fail to generate the Beveridge curve. In order to emphasize this point, results from the simulation of a standard search model with idiosyncratic match productivity would be helpful. For this, I will present simulations from an extension of the standard model laid out in the next section but does not feature on-the-job search. 


\begin{tabular}{llllllll}
\hline \hline \multicolumn{6}{c}{ Table 3: } & MP & Model with Endogenous Separation \\
\hline \hline & $u$ & $v$ & $v / u$ & u-e & $e-u$ & $z$ \\
\hline Std & 0.09 & 0.03 & 0.07 & 0.06 & 0.11 & 0.02 \\
Auto & 0.78 & 0.69 & 0.81 & 0.82 & 0.83 & 0.81 \\
Cross & Correlations & & & & \\
\hline$u$ & & 0.94 & -0.99 & -0.99 & 0.72 & -0.99 \\
$v$ & & & -0.88 & -0.88 & 0.73 & -0.88 \\
$v / u$ & & & & 0.99 & -0.69 & 0.99 \\
u-e & & & & -0.62 & 0.99 \\
$e-u$ & & & & & & -0.69 \\
\hline
\end{tabular}

Simulations in Table 3 indicate that endogenizing separations imply a positive correlation between unemployment and vacancies. The correlation turns out to be 0.94 in contrast to the empirical counterpart of -0.89 . The model proposed in this paper not only reconciles endogenous separations with a downward sloping Beveridge curve but also increases the amplification lacked in the standard model.

Finally, the U.S. data indicates that most of the variations in unemployment and vacancies are due to more variable job finding probabilities. The artificial probability series constructed by using (1) and (2) indicate that, it is the hiring which varies more over the cycle. The standard deviation of the job finding probability is almost two times greater than that of separations. Their cyclical variations are presented in Figures 5 and 6 . Although on-the-job search introduced in this paper implies another possible transition, namely $e$-e transition, these probabilities are still useful benchmarks to compare.

\section{The Economic Environment}

The model I present here is an extended version of Pries and Rogerson (2005). They study implications of different labor market institutions on hiring policies and labor market flows. Their model incorporates symmetric incomplete information into the standard search model. Symmetric incomplete information motivates agents to learn about their match quality over 
time by observing idiosyncratic component of their output. This mechanism causes persistent idiosyncratic match specific productivity. Alternatively, one could assume a slightly more complicated persistent exogenous process that governs idiosyncratic component of matches. However, as Nagypal (2004b) argues, learning about match quality is the key determinant of match specific capital especially after first few months of tenure. Hence, learning about match quality provides an empirically relevant story about productivity changes over the job. In addition, I add two key features to this model to explain the amplification puzzle: On-the-job search and aggregate uncertainty.

There is a continuum of risk neutral workers and employers who discount the future at the rate $\beta \in(0,1)$. The measure of workers is normalized to 1 . Workers and employers come together in a labor market which is characterized by search frictions.

\subsection{Learning and Production Technology}

Employers are endowed with a production technology that produces $y_{t} \in Y=\left\{y^{h}, y^{l} \mid y^{h}>\right.$ $\left.y^{l}\right\} \subset \mathbb{R}_{++}$when matched with a worker. Hence, when a worker and a firm form a productive match, they produce $z_{t} y_{t}$, which depends on the inherent match quality and aggregate state, $z_{t}$. Aggregate productivity is governed by a Markov process, $\Psi\left(z_{t+1} \mid z_{t}\right)$ and is independent of the idiosyncratic component. Even though both workers and firms observe the match specific component of the output, $y_{t}$, and the aggregate state, they do not observe their actual match quality, $q$, which can be good or bad. Match specific output is determined by the following relationship ${ }^{3}$ :

$$
\begin{aligned}
& \operatorname{Pr}\left(y_{t}=y^{h} \mid q=g\right)=\Pi_{g}>\operatorname{Pr}\left(y_{t}=y^{l} \mid q=g\right)=1-\Pi_{g} \\
& \operatorname{Pr}\left(y_{t}=y^{l} \mid q=b\right)=\Pi_{b}>\operatorname{Pr}\left(y_{t}=y^{h} \mid q=b\right)=1-\Pi_{b}
\end{aligned}
$$

Though $q$ is unobservable, agents receive an initial signal $\gamma_{0} \in[0,1]$ that corresponds to the probability that the match will be good if formed. It is same for both the worker and the

\footnotetext{
${ }^{3}$ This is slightly different from Pries and Rogerson (2005) and allows for long term learning. It could be interpreted as a reduced form learning process that in effect is governed as in Jovanovic (1979).
} 
firm. This initial signal is received from a truncated normal distribution, i.e $\gamma_{0} \sim \Gamma(\eta, \sigma)^{4}$. This distribution is time invariant. After the initial period, both parties start learning abouth their match quality based on output realizations. Since there is no asymmetric information and the output is observed by both, they will have the same posterior belief about the match quality. Let $\operatorname{Pr}\left(q=g \mid y_{t-1}\right)=\gamma$ denote this probability that the current match is a good match conditional on the past output realization on the match, $y_{t-1}$. Agents need to infer $\operatorname{Pr}\left(q=g \mid y_{t}\right)$ and $\operatorname{Pr}\left(q=b \mid y_{t}\right)$ for $y_{t} \in\left\{y^{h}, y^{l}\right\}$. At this point, it may be useful to compute the posteriors. It follows from simple Bayesian inference.

$$
\operatorname{Pr}\left(q=g \mid y_{t}=y\right)=\frac{\operatorname{Pr}\left(q=g \mid y_{t-1}\right) \operatorname{Pr}\left(y_{t}=y \mid q=g\right)}{\operatorname{Pr}\left(q=g \mid y_{t-1}\right) \operatorname{Pr}\left(y_{t}=y \mid q=g\right)+\operatorname{Pr}\left(q=b \mid y_{t-1}\right) \operatorname{Pr}\left(y_{t}=Y-y \mid q=b\right)}
$$

After some algebra, I arrive at the following posteriors implied by prior belief, $\gamma$, and time t output realization.

$$
\begin{aligned}
& \operatorname{Pr}\left(q=g \mid y_{t}=y^{h}\right)=\gamma^{h}=\frac{\gamma \Pi_{g}}{\gamma \Pi_{g}+(1-\gamma)\left(1-\Pi_{b}\right)} \\
& \operatorname{Pr}\left(q=g \mid y_{t}=y^{l}\right)=\gamma^{l}=\frac{\gamma\left(1-\Pi_{g}\right)}{\gamma\left(1-\Pi_{g}\right)+(1-\gamma) \Pi_{b}}
\end{aligned}
$$

The posterior is updated to $\gamma^{h}$ after observing a high output and to $\gamma^{l}$ after low output. Intuitively, $\gamma^{h}$ is expected to be higher than the current state $\gamma$. More formally, the current state is related to the future state in the following way under (3).

Remark 1 If (3) holds, $\gamma^{h}(\gamma) \geq \gamma \geq \gamma^{l}(\gamma)$ and both $\gamma^{h}(\gamma)$ and $\gamma^{l}(\gamma)$ are increasing in $\gamma$. In addition, $\gamma^{h}(\gamma)$ is concave whereas $\gamma^{l}(\gamma)$ is convex ${ }^{5}$.

This remark summarizes the information revelation process over time. An important feature of this learning mechanism is that it rules out any strategic action by both parties to influence the learning process. The evolution of the beliefs is entirely governed by the exogenous process

\footnotetext{
${ }^{4}$ Because $\gamma$ is restricted to be in the unit interval, $\Gamma(\eta, \sigma)$ represents the cdf of a normal distribution with parameters $\hat{\eta}$ and $\hat{\sigma}$ which is appropriately reweighted to be well defined. Hence, a pair of parameters of the actual distribution $(\hat{\eta}, \hat{\sigma})$ implies a corresponding pair for $\Gamma,(\eta, \sigma)$.

${ }^{5}$ The fact that these two mappings are increasing in $\gamma$ could be established by the positive sign of the first derivatives. Also, comparing $\gamma^{h}, \gamma^{l}$ and $\gamma$, one can easily establish that $\gamma^{h}(\gamma) \geq \gamma \geq \gamma^{l}(\gamma)$ is true. Concavity of $\gamma^{h}(\gamma)$ and convexity of $\gamma^{l}(\gamma)$ follow from these arguments and the fact that both $\gamma^{h}$ and $\gamma^{l}$ maps [0,1] to itself.
} 
defined in (3) and $(4)^{6}$. As the firm receives high output realizations, its anticipation that the match is indeed of good quality increases. The opposite is true for a firm that keeps receiving low output realizations. Furthermore, the higher the initial prior about the match quality, the higher the next period's state variable.

Finally for simplicity, I refer to the unconditional probability of observing a high output (low output) at each period as $\alpha(1-\alpha)$ in the rest of the paper. They are simply defined as linear functions of $\gamma: \alpha(\gamma)=\gamma \Pi_{g}+(1-\gamma)\left(1-\Pi_{b}\right),(1-\alpha(\gamma))=\gamma\left(1-\Pi_{g}\right)+(1-\gamma) \Pi_{b}$.

The presence of match specific productivity implies that all matches are indexed by their quality $(\gamma)$ at any point in time. This requires a way of describing the heterogeneity at any point in time. A mapping that gives the measure of the employment at any subset of the match quality state space is a natural way of describing this heterogeneity. Let $n_{t}(\gamma) \in[0,1]$ be the total number of matches that are believed to be good quality with probability $\gamma$. Since, each match employs one worker, this also gives the total number of employed workers with match quality index $\gamma$. I also assume that agents are rational in their expectations. In other words, $\gamma$ fraction of all matches among $n_{t}(\gamma)$ are actually good quality. How this distribution evolves over time depends both on the endogenous decisions made by agents and the equation of motion for aggregate productivity. I assume that this is summarized by a function $G$ such that:

$$
n_{t+1}=G\left(n_{t}, z_{t}, z_{t+1}\right)
$$

In the discussion of the equilibrium, employment distribution and (5) plays a critical role.

\subsection{Matching Technology and Wage Determination}

The meeting process is facilitated by an aggregate matching function, which maps the number of searchers on both sides of the market into meetings. Since this paper focuses on the

\footnotetext{
${ }^{6}$ This exogenous process dictated by learning for the evolution of match specific output can be thought of as any exogenous persistent match specific productivity shock where the state space and the transition probabilities are defined appropriately. For instance, a process for this match specific component may take values ranging from $\alpha(0) y^{h}+(1-\alpha(0)) y^{l}$ to $\alpha(1) y^{h}+(1-\alpha(1)) y^{l}$ and the transition probability from the current state $\gamma$ to the future state might be defined as $\operatorname{Pr}\left(\gamma^{h} \mid \gamma\right)=\alpha(\gamma)$ and $\operatorname{Pr}\left(\gamma^{l} \mid \gamma\right)=1-\alpha(\gamma)$.
} 
importance of the match quality distribution on reallocation over business cycles, search effort will be ignored. This is not an unusual assumption in labor market search models, where search input into the matching function is generally approximated by the number of unemployed. Due to on-the-job search in this paper, search input is approximated by the measure of all searchers, which equals the entire labor force ${ }^{7}$. The fact that both employed and unemployed workers meet a vacancy this does not imply that employed workers find jobs at the same rate as unemployed workers do. Idiosyncratic match quality generates endogenously different matching rates for all workers.

The matching technology is summarized by a constant returns to scale matching function, $M\left(v_{t}, 1\right)$, that takes the amount of job seekers, 1 , and vacancies, $v_{t}$ as its arguments ${ }^{8}$. This implies that the rate at which workers meet a job opportunity is $f\left(v_{t}\right)=M\left(v_{t}, 1\right) / 1$. Similarly, a vacancy will meet a worker at the rate $h\left(v_{t}\right)=M\left(v_{t}, 1\right) / v_{t}$. The meeting rate is not equal to matching rate in this model, because not all meetings end as successful matches. There are two possible types of meetings in this framework; meetings between an unemployed worker and a vacancy, and meetings between an employed worker and a vacancy. Meetings between an unemployed worker and a vacant firm turns into productive matches if their common beliefs about the match quality are above a certain threshold, which is to be determined endogenously in the equilibrium. When an already employed worker meets a vacancy, she has to decide whether to stay in her current match. This decision depends not only on the possible quality of the prospective match (if formed), but also on the quality of her existing match. Agents' initial signal about the quality of the potential match is also drawn from $\Gamma$. As a result, if the worker quits and changes her job, the firm becomes idle and can choose to post a vacancy next period.

For simplicity, I assume that there is no recall of past job offers and no wage bidding by firms to attract a worker. Incorporating a strategic interaction between a worker's current employer and a potential employer might change the results presented here at the expense of compli-

\footnotetext{
${ }^{7}$ Alternatively, one can assume negligible costs for exerting search effort for all workers to ensure that both unemployed and employed workers search for a job.

${ }^{8}$ Since not all meetings result in a match, the term "matching" is used for meeting, in the context of this paper.
} 
cating the wage determination mechanism. This simplifying assumption is not uncommon in the literature (Nagypal, 2005). Furthermore, this paper aims to provide a mechanism for amplification through the effects of labor market search on the entire employment distribution but not on wage determination.

The firm pays a wage that is determined by a sharing rule over the match surplus which is common in the literature ${ }^{9}$. The sharing rule is such that workers keep $\phi \in(0,1)$ fraction of the match surplus whereas firms get $(1-\phi)$ of it. Wages are renegotiated each period by splitting the surplus with the same rule. This does not preclude persistence in wages because inherent match quality, $\gamma$, and aggregate productivity, $z$, are both persistent. Under these assumptions about wage determination, it is clear that a worker already employed in a match with $\gamma$ probability of being a good match is willing to switch to a new employer if she faces a higher initial signal. Thus, she experiences a job-to-job transition if new signal, $\gamma_{0}$, is greater than the current match quality, i.e. $\gamma_{0}>\gamma^{10}$. If the current employment distribution is $n_{t}$, then the probability that an employed worker, conditional on meeting, is willing to switch jobs is a function of this distribution:

$$
\int n_{t}(\gamma)(1-\Gamma(\gamma)) d \gamma
$$

This is the essential feature of the model that introduces the employment distribution into the state space.

Finally, the alternative to a match for a firm is posting a vacancy, which $\operatorname{costs} c>0$ units of consumption per period and generates a possibility of a new match in the next period. Firms have incentive to post vacancy as long as the value of posting one is positive. This is ensured by the free entry of firms and implies that equilibrium value of vacancy is driven to zero. For workers, the outside option is to be unemployed and to consume $b>0$, which could be interpreted as unemployment benefits or value of leisure. This implies that ongoing

\footnotetext{
${ }^{9}$ This is equivalent to Nash Bargaining when there is no on-the-job search. Shimer (2003) analyses strategic bargaining in a model of on the job search.

${ }^{10} \mathrm{I}$ assume, throughout the rest of the analysis, that she retains the match when indifferent. It is intuitive to suggest that not all workers will be willing to change jobs if it is costly enough. This will only require a certain premium over the current match and reduce some job-to-job transitions. However, for empirically plausible values for such costs it does not eliminate job-to-job transitions, hence the mechanism underlined in this paper.
} 
matches are destroyed endogenously when the match surplus becomes negative. Because of the particular sharing rule I use, such a decision does not create any disagreements, i.e. both parties agree to end the match jointly. In the equilibrium, this implies a reservation prior, $\bar{\gamma}$. below which the match ceases to be productive and dissolves. On the other hand, a worker may unilaterally end a match, if she meets another vacancy and gets a better initial match quality signal. As explained in the previous paragraph, firms should take the possibility of such a decision into account when they are in a match. Hence, on-the-job search introduces possible match destruction, even though the surplus of the match is strictly positive. Matches are also subject to an exogenous shock in each period that renders the match unproductive. This probability is denoted by $\lambda^{11}$.

\subsection{Timing of Events}

It would be instructive to describe the timing of events within a period to understand agents' information set at each point in time. Events with a time period follows the sequence below, which is also depicted in a chart at the end of the paper:

- Matches that were productive in the last period start the period $t$ with the information, $\gamma_{t}, z_{t}$ and $n_{t}$. Unemployed workers and vacant firms start the period with $z_{t}$ and $n_{t}$.

- Workers and firms within a match decide whether to stay or exit the match. Because of the surplus sharing rule, there is no disagreement between two parties.

- If the decision is to stay, production occurs, $y_{t}$ is realized. Workers consume wages, firm consumes net output. Match quality is updated to $\gamma_{t+1}$.

- If the decision is to exit, worker becomes an unemployed searcher and consumes $b$. Firm becomes idle.

- After production, match quality distribution changes to $n_{t}^{+}$, which is different from $n_{t}$ due to learning and endogenous separations.

\footnotetext{
${ }^{11}$ This exogenous probability ensures that in the nonstochastic steady state of this economy we have a nondegenerate employment distribution over match quality space.
} 
- Firms decide to post vacancy at the cost of $c$ until the value of a vacant position is driven to zero. This pins down the total number of vacancies, $v_{t}$.

- Meetings occur according to $M\left(v_{t}, 1\right)$, and initial signals are drawn from $\Gamma$.

- Employed worker who meets a vacancy quits and changes her job if the new signal indicates a higher quality match. This decision is unilateral.

- Unemployed worker who meets a vacancy decides whether to form a match or stay unemployed.

- New matches are formed, which will be productive in $t+1$. Existing matches are subject to exogenous destruction with probability $\lambda$.

- Match quality distribution is updated to $n_{t+1}$.

\subsection{Bellman Equations}

In order to define the equilibrium of this economy, I start with the Bellman equations that determine values of being in different labor market states. State variables for agents form a list $\{\gamma, z, n\}$, where $n$ is the aggregate employment distribution and time subscripts are dropped for convenience. Aggregate state variables $z$ and $n$ are not correlated with the law of motion for the individual state variable $\gamma$, since the learning process is independent of the aggregate state $^{12}$. Equation of motion for $\gamma$ is given by posteriors defined in (4), whereas that of $z$ is governed by the Markov process. The part of the law of motion that concerns $n(\gamma)$ is denoted by $G$ such that $n^{\prime}=G\left(n, z, z^{\prime}\right)$, where the variables with "'" denote one period ahead variables. Knowing the aggregate state allows agents to predict future meeting rates.

Let $V_{u}(z, n)$ be the value of being unemployed for a worker when aggregate productivity is $z$ and the employment distribution is $n$.

$$
V_{u}(z, n)=b+\beta E_{z^{\prime} \mid z}\left\{f(v) \int V_{e}\left(\gamma^{\prime}, z^{\prime}, n^{\prime}\right) d \Gamma\left(\gamma^{\prime}\right)+(1-f(v)) V_{u}\left(z^{\prime}, n^{\prime}\right)\right\}
$$

\footnotetext{
${ }^{12}$ The matches that will survive in different aggregate states will be a function of the aggregate state in equilibrium. What I mean here is that conditional on survival of the match in the next period posterior is only determined by the exogenous learning process.
} 
An unemployed worker consumes $b$ in this period and expects to come up with a possible match with probability $f(v)$, in which case, she gets the value of having a match, denoted by $V_{e}\left(\gamma^{\prime}, z^{\prime}, n^{\prime}\right)$. Alternatively, she will stay unemployed with probability $1-f(v)$. Expectation operator takes $\Psi\left(z^{\prime} \mid z\right)$ into account and $n^{\prime}$ is governed by $G\left(n, z, z^{\prime}\right)$.

The value of having a match which is of good quality with probability $\gamma$ is slightly more complicated.

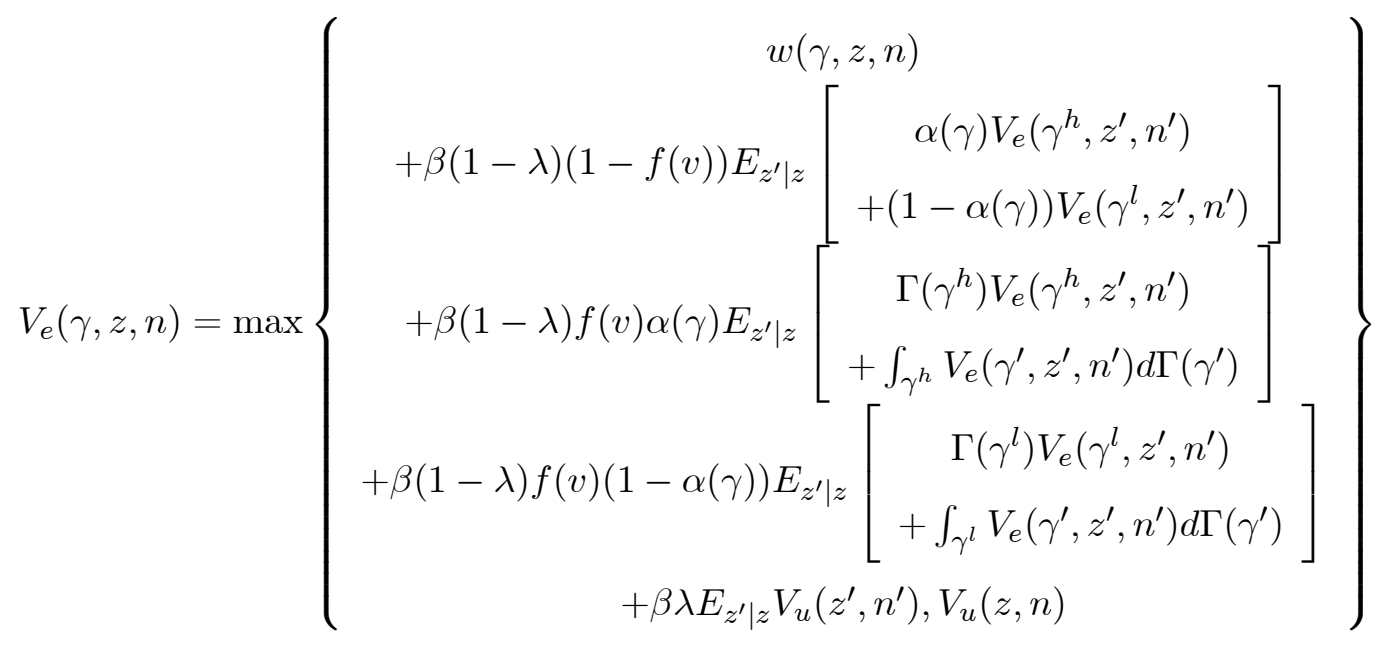

The worker compares the returns on retaining the match and not accepting or dissolving it. First five terms within the maximum operator define the discounted expected value of forming (or staying with) the match. Current return from the match equals wage payments, $w(\gamma, z, n)$. Expected value of staying in the match has three components. First, the worker might not meet another vacancy with probability $\beta(1-\lambda)(1-f(v))$ and stay with her current employer. In this case, depending on the current output realization, she will update her belief about the quality of the match according to (4). Since a high output is realized with probability $\alpha(\gamma)$, the expected future value of the match becomes $V_{e}\left(\gamma^{h}, z^{\prime}, n^{\prime}\right)$. Alternatively, a low output realization leads to a lower posterior and a corresponding expected future value of being in a match, $V_{e}\left(\gamma^{l}, z^{\prime}, n^{\prime}\right)$. The latter two terms state what happens when worker meets a new vacancy. She faces a new vacancy with probability $\beta(1-\lambda) f(v) \alpha(\gamma)$ after recently producing high output. Depending on the result of the new draw from the distribution $\Gamma$, either the current match survives or 
the worker experiences a job-to-job transition. Current match survives, if the new draw falls below $\gamma^{h}$ and dissolves otherwise. Once again, note that this separation is initiated by the worker. On the other hand, a new meeting might occur following a low output, which happens with probability $\beta(1-\lambda) f(v)(1-\alpha(\gamma))$. Worker's choice between her current match and the new vacancy is determined similarly. Finally, the match might exogenously dissolve due to an exogenous shock with probability $\lambda$.

Firm's problem could be defined in terms of Bellman equations in a similar fashion. Let $J_{u}(z, n)$ and $J_{e}(\gamma, z, n)$ be values of having a vacant job and being in a match respectively.

$$
J_{u}(z, n)=-c+\beta E_{z^{\prime} \mid z}\left\{h(v) \mu \int J_{e}\left(\gamma^{\prime}, z^{\prime}, n^{\prime}\right) d \Gamma\left(\gamma^{\prime}\right)+(1-h(v) \mu) J_{u}\left(z^{\prime}, n^{\prime}\right)\right\}
$$

Posting a vacancy costs $c$ per period and ensures that the firm will meet a worker in the next period with probability $h(v)$. Conditional on meeting with a worker, firm ends up forming a match with probability $\mu$, which is a function of the employment distribution and is defined in detail in the following section.

On the other hand, the position might stay vacant either because the contacted worker does not accept the match (with probability $h(v)(1-\mu)$ ) or the position could not meet any worker at all (with probability $1-h(v)$ ).

$$
J_{e}(\gamma, z, n)=\max \left\{\begin{array}{c}
z\left(\alpha(\gamma) y^{h}+(1-\alpha(\gamma)) y^{l}\right)-w(\gamma, z, n) \\
+\beta(1-\lambda)(1-f(v)) E_{z^{\prime} \mid z}\left[\begin{array}{c}
\alpha(\gamma) J_{e}\left(\gamma^{h}, z^{\prime}, n^{\prime}\right) \\
+(1-\alpha(\gamma)) J_{e}\left(\gamma^{l}, z^{\prime}, n^{\prime}\right)
\end{array}\right] \\
+\beta(1-\lambda) f(v) \alpha(\gamma) E_{z^{\prime} \mid z}\left[\begin{array}{c}
\Gamma\left(\gamma^{h}\right) J_{e}\left(\gamma^{h}, z^{\prime}, n^{\prime}\right) \\
+\left(1-\Gamma\left(\gamma^{h}\right)\right) J_{u}\left(z^{\prime}, n^{\prime}\right)
\end{array}\right] \\
+\beta(1-\lambda) f(v)(1-\alpha(\gamma)) E_{z^{\prime} \mid z}\left[\begin{array}{c}
\Gamma\left(\gamma^{l}\right) J_{e}\left(\gamma^{l}, z^{\prime}, n^{\prime}\right) \\
+\left(1-\Gamma\left(\gamma^{l}\right)\right) J_{u}\left(z^{\prime}, n^{\prime}\right)
\end{array}\right] \\
+\beta \lambda E_{z^{\prime} \mid z} J_{u}\left(z^{\prime}, n^{\prime}\right), J_{u}(z, n)
\end{array}\right\}
$$

A firm that starts the current period with a match that is of good quality with probability 
$\gamma$, has to decide whether to go on with this arrangement and pay $w(\gamma, z, \mu)$ to the worker or destroy the match (or not start the match at all). In the latter case, payoff to the firm is simply the value of being a vacant job. Current return from the match to the firm is the expected net output which is defined as $z\left(\alpha(\gamma) y^{h}+(1-\alpha(\gamma)) y^{l}\right)-w(\gamma, z, \mu)$. Once the firm stays with this match, worker's possible meetings with new vacancies should be taken into account to determine the discounted expected future value. For instance, the firm's employee might contact a new vacancy with probability $\beta(1-\lambda) f(v)$. When there is no new meeting in the next period, which happens with probability $\beta(1-\lambda)(1-f(v))$, expected value of the current match only depends on how beliefs and the aggregate state change. However, whenever the firm's employee contacts a new vacant position, the future of the match depends on worker's choice because of the absence of any wage bidding. For instance, a new vacancy is contacted by the worker following a high output with probability $\beta(1-\lambda) f(v) \alpha(\gamma)$, and the match will be destroyed (retained) with probability $\left(1-\Gamma\left(\gamma^{h}\right)\right)\left(\Gamma\left(\gamma^{h}\right)\right)$. If the current period output turns out to be low, these probabilities change accordingly. Finally, the match may end due to an exogenous shock, leaving the firm with a vacancy.

\section{$5 \quad$ Equilibrium}

There are four endogenous decisions to be made by the agents in this economy: Workers' and firms' decision as to when to destroy an existing match, workers' choice to unilaterally end the match to make a job-to-job transition, firms' decision on how many vacancies to create and the wage to be paid. Among them the second decision is trivial and has already been substituted in the Bellman equations in the previous section. It simply implies that a worker will not accept any new job match, if the prior about the match specific quality in this new offer falls below her belief about her current match quality. Hence, in what follows, I focus on the other three decisions.

Let $\chi(\gamma, z, n)$ denote the optimal decision rule on match formation (and destruction) and $v(z, n)$ denote the number of vacancies posted in equilibrium as a function of the aggregate state. Then the equilibrium of this economy can be easily defined. 
Definition 2 The equilibrium of this economy is a list $w(\gamma, z, n), v(z, n), \chi(\gamma, z, n), J_{e}(\gamma, z, n)$, $J_{u}(z, n), V_{e}(\gamma, z, n), V_{u}(z, n)$ and $G\left(n, z, z^{\prime}\right)$ such that;

1. Given $w(\gamma, z, n), v(z, n), \chi(\gamma, z, n)$ and $G\left(n, z, z^{\prime}\right)$, value functions satisfy (7)-(10)

2. Given $w(\gamma, z, n), v(z, n), G\left(n, z, z^{\prime}\right)$ and value functions, $\chi(\gamma, z, n)$ is optimal.

3. (Free entry of firms) Given $w(\gamma, z, n), \chi(\gamma, z, n), v(z, n)$ and $G\left(n, z, z^{\prime}\right)$, each firm posts a vacancy as long as $J_{u}(z, n)>0$. Hence, aggregate $v(z, n)$ makes the value of posting a vacancy zero, i.e. $J_{u}(z, n)=0, \forall z, n$.

4. (Surplus Sharing) Each period: $V_{e}(\gamma, z, n)-V_{u}(z, n)=\phi\left[J_{e}(\gamma, z, n)-J_{u}(z, n)+V_{e}(\gamma, z, n)-V_{u}(z, n)\right]$ and $J_{e}(\gamma, z, n)-J_{u}(z, n)=(1-\phi)\left[J_{e}(\gamma, z, n)-J_{u}(z, n)+V_{e}(\gamma, z, n)-V_{u}(z, n)\right]$.

5. Decision rules $w(\gamma, z, n), v(z, n)$, and $\chi(\gamma, z, n)$ indeed generate $G\left(n, z, z^{\prime}\right)$ subject to Bayesian updating and equation of motion for $z$.

The specific surplus sharing rule used in this paper implies that both workers and firms agree to leave when the surplus of the match falls below zero. Surplus of the match is defined as the quantity, $J_{e}(\gamma, z, n)-J_{u}(z, n)+V_{e}(\gamma, z, n)-V_{u}(z, n)$. When the match surplus is negative, the share each party gets become negative simultaneously. Hence, in order to describe the decision rule $\chi(\gamma, z, n)$, it is essential to write down the surplus function. Subtracting outside options from $J_{e}(\gamma, z, n)$ and $V_{e}(\gamma, z, n)$, and adding them up leads to an expression defining the value of the surplus from a match with quality $\gamma$, in aggregate state $z$ and $n$. Details of the derivation is presented in the appendix. Let this value be denoted by $S(\gamma, z, n)$. The appendix shows that this surplus function has the following recursive form.

$$
S(\gamma, z, n)=\max \left\{\begin{array}{c}
z\left(\alpha(\gamma) y^{h}+(1-\alpha(\gamma)) y^{l}\right)-b \\
+\beta(1-\lambda)(1-f(v)) E_{z^{\prime} \mid z}\left[\alpha(\gamma) S\left(\gamma^{h}, z^{\prime}, n^{\prime}\right)+(1-\alpha(\gamma)) S\left(\gamma^{l}, z^{\prime}, n^{\prime}\right)\right] \\
+\beta(1-\lambda) f(v) \alpha(\gamma) E_{z^{\prime} \mid z}\left[\Gamma\left(\gamma^{h}\right) S\left(\gamma^{h}, z^{\prime}, n^{\prime}\right)+\phi \int_{\gamma^{h}} S\left(\gamma^{\prime}, z^{\prime}, n^{\prime}\right) d \Gamma\left(\gamma^{\prime}\right)\right] \\
+\beta(1-\lambda) f(v)(1-\alpha(\gamma)) E_{z^{\prime} \mid z}\left[\Gamma\left(\gamma^{l}\right) S\left(\gamma^{l}, z^{\prime}, n^{\prime}\right)+\phi \int_{\gamma^{l}} S\left(\gamma^{\prime}, z^{\prime}, n^{\prime}\right) d \Gamma\left(\gamma^{\prime}\right)\right] \\
-\beta E_{z^{\prime} \mid z} f(v) \phi \int S\left(\gamma^{\prime}, z^{\prime}, n^{\prime}\right) d \Gamma\left(\gamma^{\prime}\right),
\end{array}\right\}
$$


subject to $\Psi\left(z^{\prime} \mid z\right)$ and $G\left(n, z, z^{\prime}\right)$.

This equation is one of the key equations characterizing the equilibrium. For any $v>0$, this equation describes when an existing match should be destroyed bilaterally. Since the right part of the expression within the outermost bracket is constant and the left is increasing in $\gamma$, it is easy to show that the decision rule $\chi(\gamma, z, n)$ takes the following form for a given $v$.

$$
\chi(\gamma, z, n)=\left\{\begin{array}{l}
1 \text { if } \gamma \geq \bar{\gamma}(z, n) \\
0 \text { if } \gamma<\bar{\gamma}(z, n)
\end{array}\right.
$$

The reservation threshold, $\bar{\gamma}(z, n)$, determines whether a match should survive. It also summarizes the hiring decision. In other words, a meeting will turn into a match if the reservation threshold is reached and an ongoing match is terminated if the match quality falls below this threshold. In equilibrium, it turns out that $\bar{\gamma}(z, n)$ is a decreasing function of $z$. Intuitively, agents become less willing in recessions to undertake matches that are less probable to be good quality. Since all matches are less productive the threshold for a match to survive is higher in recessions. This particular form of the decision rule causes discrete changes in employment distribution across different aggregate productivity levels. For instance, when productivity falls, all prevailing matches that have current priors below the new (and higher) threshold will be destroyed endogenously. Hence, some existing matches that are productive in expansions cease to be so in recessions, causing countercyclical job destruction.

The second important equation determining the equilibrium of this economy comes from the free entry condition and pins down the equilibrium number of vacancies posted. As it is shown in the appendix, the value of vacancy can be written as a function of the surplus function. It takes a simple form:

$$
J_{u}(z, n)=-c+\beta E_{z^{\prime} \mid z} J_{u}\left(z^{\prime}, n^{\prime}\right)+\beta h(v) \mu(1-\phi) E_{z^{\prime} \mid z} \int S\left(\gamma^{\prime}, z^{\prime}, n^{\prime}\right) d \Gamma\left(\gamma^{\prime}\right)
$$

However, free entry of firms imply that $J_{u}(z, n)=0$ for all $z, n$ in equilibrium. Substituting this in (13) gives the second key condition describing the equilibrium. 


$$
\frac{c}{\beta h(v) \mu(1-\phi)}=E_{z^{\prime} \mid z} \int S\left(\gamma^{\prime}, z^{\prime}, n^{\prime}\right) d \Gamma\left(\gamma^{\prime}\right)
$$

Equations (11) and (14) jointly determine the equilibrium values for $v(z, n)$ and $\bar{\gamma}(z, n)$. These two equilibrium conditions are standard in models of labor market search with endogenous job destruction (Mortensen and Pissarides, 1994). Given the law of motions $G\left(n, z, z^{\prime}\right)$ and $\Psi\left(z^{\prime} \mid z\right)$ for the aggregate state, they characterize part of the equilibrium definition.

The rest of the equilibrium requires describing the endogenous equation of motion for the aggregate match quality distribution. Equilibrium definition requires that the decision rules determined by (11) and (14) should be consistent with the equation of motion for the match quality distribution, $G\left(n, z, z^{\prime}\right)$. The presence of this distribution significantly complicates the numerical solution. Thus, I leave the discussion of this last component of the equilibrium to the following section, which describes the practical challenges of the computational problem and the solution method employed.

\subsection{Employment Flows}

In order to shed more light on the mechanism advocated in this paper, it is essential to understand how match quality distribution evolves over time. Let $n_{t-1}$ be the match quality distribution at the end of time period $t-1$. I assume that agents, both workers and firms, are rational in their expectations about match quality. In other words, among the matches that are currently believed to be good with probability $\gamma$, fraction of the good matches are indeed $\gamma$.

From any distribution $n_{t-1}$, decision rules $v\left(z_{t}, n_{t}\right), \chi\left(\gamma, z_{t}, n_{t}\right)$ and law of motion $G\left(n_{t-1}, z_{t-1}, z_{t}\right)$, generate the employment distribution for time period $t$ : 
$n_{t}(\gamma)=\chi\left(\gamma, z_{t}, n_{t}\right)\left\{\begin{array}{c}(1-\lambda) \alpha\left(\gamma_{1}\right)\left\{1-f\left(v\left(z_{t}, n_{t}\right)\right)\left[1-\Gamma\left(\gamma_{1}\right)\right]\right\} n_{t-1}\left(\gamma_{1}\right) \\ +(1-\lambda)\left(1-\alpha\left(\gamma_{2}\right)\right)\left\{1-f\left(v\left(z_{t}, n_{t}\right)\right)\left[1-\Gamma\left(\gamma_{2}\right)\right]\right\} n_{t-1}\left(\gamma_{2}\right) \\ +(1-\lambda) f\left(v\left(z_{t}, n_{t}\right)\right) \int_{0}^{\gamma^{1}} \alpha\left(\gamma^{\prime}\right) n_{t-1}\left(\gamma^{\prime}\right) d \Gamma\left(\gamma^{\prime}\right) \\ +(1-\lambda) f\left(v\left(z_{t}, n_{t}\right)\right) \int_{0}^{\gamma^{2}}\left(1-\alpha\left(\gamma^{\prime}\right)\right) n_{t-1}\left(\gamma^{\prime}\right) d \Gamma\left(\gamma^{\prime}\right) \\ +f\left(v\left(z_{t}, n_{t}\right)\right)\left(1-\int_{0}^{1} n_{t-1}\left(\gamma^{\prime}\right) d \gamma^{\prime}\right) g(\gamma)\end{array}\right\}, \forall \gamma \in[0,1]$

where $g(\gamma)$ denotes the pdf of the distribution function $\Gamma(\gamma)$, and $\gamma_{1}$ and $\gamma_{2}$ are defined as;

$$
\gamma=\frac{\gamma^{1} \Pi_{g}}{\gamma_{1} \Pi_{g}+\left(1-\gamma_{1}\right)\left(1-\Pi_{b}\right)} \text { and } \gamma=\frac{\gamma_{2}\left(1-\Pi_{g}\right)}{\gamma_{2}\left(1-\Pi_{g}\right)+\left(1-\gamma_{2}\right) \Pi_{b}}
$$

This recursive definition for employment distribution tracks down employment reallocation across different quality matches over time. To better understand the notation, it is helpful to think where workers should have been in the last period to end up in matches with a particular match quality $\gamma$. First of all, some fraction of workers with this match quality constitutes new hires from the unemployed. This corresponds to the last term in brackets in (15). Previously unemployed workers meet a vacancy with probability $f\left(v\left(z_{t}, n_{t}\right)\right)$. Hence, $f\left(v\left(z_{t}, n_{t}\right)\right)\left(1-\int_{0}^{1} n_{t-1}\left(\gamma^{\prime}\right) d \gamma^{\prime}\right)$ gives the total measure of unemployed who meet a vacancy this period. Among them, only $g(\gamma)$ of them draws the prior $\gamma$, and are candidates for a new match with $\gamma$ quality in this period. However, the decision to form the match as a result of this meeting depends on the rule, $\chi\left(\gamma, z_{t}, n_{t}\right)$. This condition implies that overall number of new hires from the unemployment pool will be equal to:

$$
f\left(v\left(z_{t}, n_{t}\right)\right)\left(1-\int_{0}^{1} n_{t-1}\left(\gamma^{\prime}\right) d \gamma^{\prime}\right)\left[1-\Gamma\left(\bar{\gamma}\left(z_{t}, n_{t}\right)\right)\right]
$$

Flows into $n_{t}(\gamma)$ might also come from already employed workers. This group of workers have potentially different histories. For instance, some of them end up in $n_{t}(\gamma)$ after a jobto-job transition. On the other hand, a fraction of these already employed workers constitute participants of matches that endogenously update their posteriors to $\gamma$ after output realizations 
in the last period. Let's consider matches which might improve their posteriors to $\gamma$, because they have recently experienced a good output realization. This happens to matches with $\gamma_{1}$ probability of being a good match in period $t-1$. Hence, they were part of $n_{t-1}\left(\gamma_{1}\right)$. Only $(1-\lambda) \alpha\left(\gamma_{1}\right)$ of $n_{t-1}\left(\gamma_{1}\right)$ experience high output and do not suffer an exogenous match destruction. Some of the workers in these matches might not meet any other vacancy at all, which happens with the probability $\left(1-f\left(v\left(z_{t}, n_{t}\right)\right)\right.$. The rest of them, however, might not be willing to change jobs even if they meet a new vacancy, which occurs with the probability $f\left(v\left(z_{t}, n_{t}\right)\right) \Gamma\left(\gamma_{1}\right)$. This completes the description of the first term within brackets in (15). The second term defines the measure of previously employed workers from matches that has experienced a low output in the last period and yet survived exogenous shocks.

The following two terms in (15) give the measure of workers who ended up in a match with $\gamma$ match quality after quitting their previous matches. If these workers have recently experienced a high output in the last period, they could potentially come from the interval $\left[0, \gamma_{1}\right]$. Otherwise, they were part of the employment distribution over $\left[0, \gamma_{2}\right]$. Note that, employment distribution by the end of period $t$, should always take $\chi\left(\gamma, z_{t}, n_{t}\right)$ into account. This part creates the separation that is endogenous.

The results in this paper show that most of the reallocation is undertaken through job-to-job transitions. A job-to-job transition necessarily implies a simultaneous separation and a new hire. Thus, it involves reallocating workers across matches.

\subsection{Computational Strategy}

Match quality distribution is part of the state space in this model. Due to (6), firms need to predict this match quality distribution. It appears explicitly in firms' Bellman equations through $\mu$ and implicitly in workers' Bellman equations. The challenge posed by the presence of aggregate distribution is not new in the literature. It is well known that numerical solutions of economies with heterogenous agents where aggregate distribution is a state variable is fairly complicated. Fortunately, Krusell and Smith (1998) provides us with a possible computational strategy to solve this type of problems. The novelty in their approach is to approximate the function $G\left(n, z, z^{\prime}\right)$ with a finite set of moments in such a way that it is consistent with 
individual's problem and is the best approximation within a particular class of functional forms. Hence, individuals use this approximate function to predict future prices and their predictions are approximately equal to the actual time series from the simulated model.

The same methodology may be applied to our problem. Krusell and Smith (1998)'s example economy is a standard neoclassical growth model with uninsured idiosyncratic individual risk of being unemployed. Hence, individuals in their economy need to predict aggregate capital stock distribution in the next period to pin down the prices that they will face tomorrow. It turns out that a log linear equation in average capital stock is a sufficient representation of how the entire distribution evolves. In our example however, agents need to predict the future match quality distribution to pin down the probability of a worker's acceptance of a new job offer.

Recall that the beginning of period match quality distribution evolves from $n_{t}$ to $n_{t}^{+}$because of the new information revealed through production and endogenous separations at the beginning of the period. Then the probability that a worker who meets a vacancy accepts firm's job offer is a function of the match quality distribution:

$$
\mu=\left(1-\int n_{t}^{+}(\gamma) d \gamma\right)(1-\Gamma(\bar{\gamma}))+\int n_{t}^{+}(\gamma)(1-\Gamma(\gamma)) d \gamma
$$

The first term in (18) gives the probability of meeting an unemployed worker and forming a match. Among those whom the firm meets (which happens at the rate $h(v))\left(1-\int n_{t}^{+}(\gamma) d \gamma\right.$ ) are unemployed workers and they receive an initial signal. If it is above the reservation threshold, $\bar{\gamma}$, it is worth to form the match. This comes from the equilibrium decision rule $\chi(\gamma, z, n)$, which takes the value 1 for $\gamma \geqslant \bar{\gamma}$ and 0 otherwise. The second term in (18) gives the probability of meeting an employed worker and forming a match. Each worker who is in a match indexed by belief $\gamma$, will accept the firm's match offer with probability $1-\Gamma(\gamma)$.

This is why, for practical purposes, it is sufficient to have a simple probability in the state space instead of the match quality distribution. The computational algorithm I use to solve for the equilibrium of this economy involves an approximation of the law of motion for $\mu$. So, even though the match quality distribution is changing over time, agents need to know how 
a simple moment of this distribution changes over time. For any equation of motion defined by $G\left(n, z, z^{\prime}\right)$, there is an implied equation of motion for $\mu^{13}$. Let the equation of motion implied be $H\left(\mu, z, z^{\prime}\right)$. Given this belief and the stochastic process for $z$, agents' problem could be solved using equilibrium conditions (11) and (14). Solution to these equilibrium conditions

lead to decision rules $\chi(\gamma, z, \mu)$ and $v(z, \mu)$, which are now defined as a function of $\mu$ for practical purposes. Then, these decision rules, an initial condition for employment distribution, equation of motion for employment, (5), and the definition for $\mu$ determine next period's probability $\mu^{\prime}$. If this $\mu^{\prime}$ is consistent with $H\left(\mu, z, z^{\prime}\right)$, we arrive at the fixed point of the mapping from $\left(\mu, z, z^{\prime}\right)$ to $\mu^{\prime}$. The next step involves determining whether $H\left(\mu, z, z^{\prime}\right)$ is a 'good' approximation for the underlying equation of motion, $G\left(n, z, z^{\prime}\right)$. This ensures that agents lack of knowledge about the evolution of the match quality distribution causes only negligible errors in optimal decisions.

The precise algorithm for the computation of the equilibrium involves following steps:

1. Select N-point grid on $\mu$, 2-point grid on $z$ and M-point grid on $\gamma$.

2. Guess on a parameterized functional form for $H\left(\mu, z, z^{\prime}\right)$ and on parameters of this function. Call this $\hat{H}$.

3. Given $\hat{H}$, guess a $\mathrm{Nx} 2$ vector, $v(z, \mu)$ and solve the decision rule $\chi(\gamma, z, \mu)$ by Iterating over the surplus function defined in recursive equation (11) until convergence. Obtain the value of $S(\gamma, z, \mu)$.

4. Given the surplus function, $S(\gamma, z, \mu)$, check whether free entry condition in (13) is satisfied. If it is satisfied, $v(z, \mu)$ is equilibrium decision rule and continue to step 5 . Otherwise, if free entry condition implies that the value of vacancy is positive in state $(z, \mu)$, increase $v(z, \mu)$, else decrease it and go to step 3 with the new guess on $v(z, \mu)$.

5. Use decision rules $\chi(\gamma, z, \mu)$ and $v(z, \mu)$ and an initial employment distribution to simulate the evolution of employment distribution. From this simulated series, estimate the implied sequence of $\mu$. Use the estimated series of $\mu$, to update the parameters of the

\footnotetext{
${ }^{13}$ This mapping may not be unique in principle.
} 
functional form guess for $H\left(\mu, z, z^{\prime}\right)$. If the initial guess on parameters are confirmed, jump to step 6 , otherwise go back to step 1 with a new set of parameter estimates.

6. Having had the parameters converged, check how much error the particular functional form for $\hat{H}$ creates for the agents. If the functional form enables them to predict probabilities with negligible error, stop. Otherwise choose a new functional form and/or new moments and start over.

Computational results show that a linear functional form for $\mu^{\prime}$ is a good guess. The details of this part of the computation is described in Section 7 below. Since computing $H\left(\mu, z, z^{\prime}\right)$ is an important contribution of this paper and is not standard in this literature, a separate section within the main body of the paper is devoted to this computation.

\section{Calibration}

In order to understand the contribution of on-the-job search to amplification, I calibrate a benchmark model, where there is no on-the-job search. This benchmark model is otherwise identical (preferences, production and matching technology) to the model presented in the preceding section. Hence, the benchmark model only has idiosyncratic match quality on top of the standard model. This helps to identify the effect of on-the-job search. The time period is one month and $\beta$ is calibrated to match $4 \%$ annual interest rate. This implies that $\beta=0.9967$.

First step is to calibrate a productivity process. This is achieved by estimating a two state Markov-Chain approximation for the $\mathrm{AR}(1)$ process for the real output per worker in the nonfarm business sector. As Table 1 indicates, this productivity data has a standard deviation of 0.02 and a first order autocorrelation of 0.89 . Since the standard deviation of this process will be affecting the volatility of other variables directly, matching the exact standard deviation would be desired. Thus I find the following Markov process as the best approximation, which implies a standard deviation of 0.02 and a first order autocorrelation of 0.81 .

$$
\Psi\left(z_{t+1} \mid z_{t}\right)=\left[\begin{array}{ll}
0.9682 & 0.0318 \\
0.0318 & 0.9682
\end{array}\right], z^{h}=1.0259 \text { and } z^{l}=0.9748
$$


Several parameters are taken from other studies. The share of the surplus taken by worker, $\phi$, is chosen to be 0.36 (Shimer, 2005a). The mean of the truncated normal density $\Gamma$ is set to 0, i.e. $\eta=0$. This is from Pries and Rogerson (2005). I also normalize the value of the match specific output when it is low to 1 , i.e. $y^{l}=1$.

The functional form for the constant returns to scale matching function is usually in CobbDouglas form in standard search models. However, since I have on-the-job search with a unit measure of search input, this particular form does not necessarily guarantee us a well defined meeting probability. In other words, $f(v)$ and/or $h(v)$ may not be well defined for some $v$. Thus, I choose a different functional form for the matching function that has been used by Barlevy (2002) and den Haan et.al (2000). Matching function takes the following simple form:

$$
M\left(v_{t}, 1\right)=\frac{v_{t}}{v_{t}+1}
$$

Equation (19) defines a constant returns to scale matching function, which obeys the usual regularity conditions. In addition, meeting probabilities within a period, $f(v)$ and $h(v)$ are by definition in $[0,1]$.

\begin{tabular}{llllll}
\hline \hline \multicolumn{2}{l}{ Calibrated Parameters } & & & \\
\hline \hline Parameter & Value & & Parameter & Value & \\
\hline$\beta$ & 0.9967 & $4 \%$ interest & $\Pi_{g}$ & 0.56 & Match \\
$\phi$ & 0.36 & Shimer (2005) & $\Pi_{b}$ & 0.56 & Restriction \\
$y^{l}$ & 1 & Normalization & $c$ & 0.11 & Match \\
$z^{h}$ & 1.0259 & U.S. Avg. & $b$ & 3.32 & Restriction \\
$z^{l}$ & 0.9748 & Output p/w & $y^{h}$ & 7 & Match \\
$\eta$ & 0 & PR (2005) & $\lambda$ & 0.0041 & DHS (1996) \\
$\sigma$ & 0.153 & PR (2005) & $z^{s s}$ & 1 & Normalization \\
\hline
\end{tabular}

In order to calibrate the rest of the parameters, I target three moments from the model; steady state unemployment rate of $5.68 \%$, steady state job finding probability of $45 \%$ and steady state probability of accepting a match conditional on meeting of $50 \%$. The first two statistics are from the data. The latter statistic equals $1-\Gamma\left(\bar{\gamma}^{s s}\right)$ and chosen to be in line with Pries and 
Rogerson (2005). These targets imply a steady state monthly separation probability of $2.71 \%$. This is slightly lower than the average separation probability in the U.S. data, which is $3.4 \%$. However, we cannot simultaneously match an average job finding probability of $45 \%$ and an average separation probability of $3.4 \%$. The exogenous job destruction probability, $\lambda$, is then calibrated to match the fraction of shutdowns among all job destruction. Davis et al. (1996) estimates that $11 \%$ of all job destruction is accounted for by shutdowns. Since all separations in the benchmark model's steady state are either exogenous (due to $\lambda$ ) or due to learning about the quality of the match, a slightly higher value for this fraction is targeted. Specifically, it is assumed that $15 \%$ of all separations are exogenous. This pins down $\lambda$, which is set to 0.0041 .

Since job finding probability is $f\left(v^{s s}\right)\left(1-\Gamma\left(\bar{\gamma}^{s s}\right)\right)$ in the steady state equilibrium of this benchmark economy, the target for $1-\Gamma\left(\bar{\gamma}^{s s}\right)$ implies that $v^{s s}=9$. Given these targets, learning process can be calibrated to match them. For instance, the standard deviation of the distribution for prior signals, $\sigma$, implies an equilibrium value for $\bar{\gamma}^{s s}$ if $\left(1-\Gamma\left(\bar{\gamma}^{s s}\right)\right)=0.5$. The value of $\bar{\gamma}^{s s}$ does not have any intrinsic value for the purpose of this paper. Hence, I target a value of 0.1 for this equilibrium value. This target and $\left(1-\Gamma\left(\bar{\gamma}^{s s}\right)\right)=0.5$, implies that $\sigma=0.153$. With the targets for $\bar{\gamma}^{s s}$ and $v^{s s}$ and values for $\lambda, \sigma$ and $\eta$, the model can be easily simulated to generate a stationary match quality distribution. Only determinants of this equilibrium distribution are learning parameters $\Pi_{g}$ and $\Pi_{b}$. Recall that these two parameters determine the pace of learning. There is no apriori reason to have a faster learning depending on the inherent quality. Hence, it is assumed in the simulations that both good matches and bad matches reveal the information at the same pace, i.e. $\Pi_{b}=\Pi_{g}$. Then, the average unemployment rate requires $\Pi_{b}=\Pi_{g}=0.598$. It turns out that the benchmark model with these set of parameters actually imply a tenure distribution that is consistent with the U.S. data. This is not a dimension that I target, but the stationary match quality distribution determines how long each match is likely to survive. Taking this into account, the benchmark model generates a tenure distribution such that $25.71 \%$ of the employed are with 1 year of tenure, $21.42 \%$ of the employed are with $3-4$ years of tenure and $23.49 \%$ of the employed are with 5-9 years of tenure. The corresponding values from BLS's Employment Tenure Summary 
are $20.7 \%, 19 \%$ and $20.7 \%$ respectively ${ }^{14}$.

Calibrating a value for $b$ is not straightforward. Recall that $y^{l}=1$. In this benchmark model, finding an interior solution for $\bar{\gamma}$, requires that the value of surplus is at least 0 for $\gamma=0$ and strictly positive for $\gamma=1$. In general, this implies that $b$ should be somewhere between $y^{h}$ and $y^{l}$. Taking this restriction into account and the targets for $\bar{\gamma}^{s s}$ and $v^{s s}$, I pick the values for $b, y^{h}$ and $c$. Implied values for these parameters are 3.32, 7 and 0.11 respectively. This completes the calibration for the benchmark model.

\section{Computing $H\left(\mu, z, z^{\prime}\right)$}

The challenging task of computing the equilibrium of this economy is already outlined in Section 4.1. The most critical step of the algorithm is to determine a good functional form for the equation of motion of $\mu^{\prime}$. I posit a linear functional form guess, which depends on both the current productivity and past productivity. Intuitively, since the model economy undergoes significant discrete changes at the lower end of the distribution when aggregate productivity changes, the equation of motion may very well depend on both states. To illustrate this, consider two stationary distributions of match quality shown in Figure 7 . The solid line represents the stationary match quality distribution implied by the model outlined in Section 3 , when aggregate productivity stays constant at $z^{l}$ forever. On the other hand, the dashed line represents the stationary match quality distribution in expansions. Because the equilibrium reservation threshold $\bar{\gamma}$ is a decreasing function of $z$, we have a substantial mass of workers with lower match qualities in expansions. Although these thresholds change in the stochastic equilibrium, this feature of the model survives. Thus, when the aggregate state changes, there will be considerable job destruction (or creation) at the lower end of the distribution. This justifies adding $z^{\prime}$ (in addition to $z$ ) to the list of independent variables determining $\mu^{\prime}$. Ultimately I use the following functional form.

\footnotetext{
${ }^{14}$ The data could be found in Table 3 of the Summary at http://www.bls.gov/news.release/tenure.t03.htm.
} 


$$
\begin{aligned}
& \mu^{\prime}=\theta_{1}+\theta_{2} \mu, \text { if } z=z^{l} \text { and } z^{\prime}=z^{l} \\
& \mu^{\prime}=\theta_{3}+\theta_{4} \mu, \text { if } z=z^{l} \text { and } z^{\prime}=z^{l} \\
& \mu^{\prime}=\theta_{5}+\theta_{6} \mu, \text { if } z=z^{l} \text { and } z^{\prime}=z^{l} \\
& \mu^{\prime}=\theta_{7}+\theta_{8} \mu, \text { if } z=z^{l} \text { and } z^{\prime}=z^{l}
\end{aligned}
$$

Once there is a functional form guess for $H\left(\mu, z, z^{\prime}\right)$ and an initial set of parameter values for $\theta^{\prime} s$, computation of the equilibrium starts by discretization of the state space $(\gamma, z, \mu)$. Aggregate productivity only takes two values, $z^{h}$ and $z^{l}$. Match quality index is defined on a 250-point grid over the unit interval. I use $\mathrm{M}=250$ grid points because the grid on $\gamma$ should be fine enough to capture the underlying individual heterogeneity. This heterogeneity determines the exact value of the equilibrium condition $\bar{\gamma}(z, n)^{15}$. Finally, $\mu$ 's are assumed to take values between 0.13 and 0.19 and are equally spaced on 15 grid points ${ }^{16}$. The upper and lower bounds on $\mu$ are chosen such that at the simulation stage none of the realized (actual) values for $\mu$ fall out of this range.

Next step is to solve the recursive equations defined in (14) and (11) using the functional guess for $H\left(\mu, z, z^{\prime}\right)$. This step is fairly standard and leads to decision rules $\chi(\gamma, z, \mu)$ and $v(z, \mu)$. Then, the model economy is simulated for 15000 periods starting from an initial distribution. The simulation length should be long enough to create enough artificial samples for states $\left(z, z^{\prime}\right)$, where $z \neq z^{\prime 17}$. Simulation of the model generates two separate time series for $\mu$ one of which is predicted by $H\left(\mu, z, z^{\prime}\right)$ and the other one is the actual. After discarding the initial several hundred periods, actual realizations of $\mu$ are used to estimate the regressions in (20) via ordinary least squares. The OLS estimates of $\theta^{\prime}$ s are used as new parameter guesses until convergence. Once parameters converge, I need to evaluate the goodness of "fit" for the particular functional form for $H\left(\mu, z, z^{\prime}\right)$.

\footnotetext{
${ }^{15}$ I have tried finer grids, but they do not seem to lead to changes on the equilibrium values for $\bar{\gamma}(z, n)$.

${ }^{16}$ Adding more grid points essentailly did not change the results at all. However, lowering the number of grids for $\mu$ will reduce the predictive power of the functional forms for states $\left(z, z^{\prime}\right)$, where $z \neq z^{\prime}$.

${ }^{17}$ Due to the persistence in $z$, these periods are very rare as opposed to periods when aggregate state does not change at all.
} 
It turns out that agents do infer $\mu^{\prime}$ with considerable precision when only $\mu, z$ and $z^{\prime}$ are explanatory variables. Regression results from the simulations of the model is a standard way of measuring how good an approximation the equilibrium is (Krusell and Smith, 1998). The following four equations show the extent of the fit.

$$
\begin{aligned}
\mu^{\prime} & =0.05044+0.69617 \mu, \text { if } z=z^{l} \text { and } z^{\prime}=z^{l} \\
R^{2} & =0.9987, F=5279389, p=0 \\
\mu^{\prime} & =0.04774+0.83172 \mu, \text { if } z=z^{l} \text { and } z^{\prime}=z^{h} \\
R^{2} & =0.9974, F=53143.60, p=0 \\
\mu^{\prime} & =0.06635+0.51251 \mu, \text { if } z=z^{h} \text { and } z^{\prime}=z^{l} \\
R^{2} & =0.9841, F=842.97, p=0 \\
\mu^{\prime} & =0.06338+0.62260 \mu, \text { if } z=z^{h} \text { and } z^{\prime}=z^{h} \\
R^{2} & =0.9974, F=2915907, p=0
\end{aligned}
$$

Parameter values reported in (21) are the values that have converged after several iterations of the same functional form, and they are all significant at $5 \%$ level of significance. All three measures of fitness reported underneath each regression equation indicate that the simple linear functional form is a good way of describing how $\mu$ evolves $^{18}$.

Other studies that modeled on-the-job search either assumed simplifying assumptions to get rid of the endogenous effects of heterogeneity through meeting rates or simply restricted the analysis to non-stochastic equilibrium. Examples of the first approach are Mortensen and Nagypal (2005) and Krause and Lubik (2004). They abstract from match specific productivity changes, which shuts off the channel through which the employment distribution becomes a state variable. As this paper argues, this channel is indeed very significant. Studies taking the latter approach fails to show the full picture. They only focus on comparing different steady states or analyzing only the transitional dynamics (Barlevy (2002), Nagypal (2005), Shimer

\footnotetext{
${ }^{18}$ Another measure of "goodness of fit" can be the discrepancy between the $\mu^{\prime}$ s implied by $H\left(\mu, z, z^{\prime}\right)$ and actual ones. It turns out that the maximum discrepancy in a period was 0.00087 . Furthermore, this difference was always less than 0.0007 in all but 9 periods (out of 15000).
} 
(2003) ). However, this paper provides a solution for the stochastic equilibrium allowing us to conduct a thorough business cycle analysis. These results are discussed in the next section.

\section{Results}

To understand the role of on-the-job search in generating labor market amplification, both the benchmark model and the model with on-the-job search are simulated. Table 4. presents the results from simulations of the model with on-the-job search. As it is evident from the reported standard deviations, the presence of on-the-job search creates significant variations in our key labor market variables. Although the underlying aggregate productivity process is assumed to be the same, a comparison of Table 4 and either Table 2 or 3 shows that the model amplifies the effects of productivity shocks to a large extent. In standard search models, unemployment, vacancies and market tightness are almost as variable as the exogenous forcing process. However, same process generates quite encouraging results in the model with on-thejob search. For instance, the standard deviation of unemployment and the Beveridge curve relationship are easily matched (See Table 1). It also implies significantly large variations in vacancies and market tightness, even though, they are a little far off from the data.

\begin{tabular}{|c|c|c|c|c|c|c|c|}
\hline & $u$ & $v$ & $v / u$ & u-e & $e-u$ & e-e & $z$ \\
\hline Std & 0.19 & 0.13 & 0.31 & 0.14 & 0.29 & 0.14 & 0.02 \\
\hline Auto & 0.88 & 0.73 & 0.84 & 0.80 & 0.67 & 0.81 & 0.81 \\
\hline \multicolumn{8}{|c|}{ Cross Correlations } \\
\hline$u$ & & -0.89 & -0.98 & -0.94 & 0.86 & -0.96 & -0.97 \\
\hline$v$ & & & 0.96 & 0.99 & -0.97 & 0.98 & 0.98 \\
\hline$v / u$ & & & & 0.99 & -0.92 & 0.99 & 0.99 \\
\hline u-e & & & & & -0.96 & 0.99 & 0.99 \\
\hline$e-u$ & & & & & & -0.95 & -0.95 \\
\hline e-e & & & & & & & 0.99 \\
\hline
\end{tabular}


One might argue that, a direct comparison between Table 2, Table 3 and Table 4 is not reasonable. This is a legitimate concern, because the implied improvements in performance might be due to one (or more) of the several extensions inherent in the model presented in Section 4. In order to distinguish the effect of on-the-job search, I compare the results from simulations of the benchmark model, which is exactly identical except the on-the-job search aspect.

\begin{tabular}{lllllll}
\hline \hline \multicolumn{7}{c}{ Table 5: Benchmark Model (No OJS) } \\
\hline \hline Std & 0.13 & 0.05 & 0.08 & 0.07 & 0.16 & 0.02 \\
Auto & 0.76 & 0.67 & 0.81 & 0.81 & 0.36 & 0.89 \\
Cross & Correlations & & & & \\
\hline$u$ & & 0.96 & -0.98 & -0.98 & 0.76 & -0.98 \\
$v$ & & & -0.90 & 0.90 & 0.78 & -0.90 \\
$v / u$ & & & & 1 & -0.71 & 0.99 \\
u-e & & & & -0.71 & 0.99 \\
$e-u$ & & & & & -0.70 \\
\hline
\end{tabular}

Simulation results for the benchmark model are presented in Table $5^{19}$. There are at least two important differences between the benchmark model and the model with on-the-job search. First of all, the standard deviations of the cyclical variations show significant decline, especially for vacancies and vacancy-unemployment ratio. This proves that the relevant mechanism for the amplification is on-the-job search. Another fact that stands out in Table 5 is related to the Beveridge curve. The correlation between unemployment and vacancies implied by the benchmark model is 0.96 . This counterfactually positive relationship is a result of the countercyclical vacancies in the benchmark model.

Without on-the-job search, equilibrium of this economy will only be a function of the level of aggregate productivity. This follows from the constant returns to scale matching function and the fact that the search input is proxied only by unemployment. Since all unemployed workers

\footnotetext{
${ }^{19}$ The difference between Table 5 and Table 3 is only because of the different functional forms used for matching function. The model that generates the simulations in Table 3 assumes a standard Cobb-Douglas form.
} 
are ex-ante identical and there are no meetings between vacancies and employed workers, the probability of forming a match for a firm only depends on the $v / u$ ratio. For two different unemployment levels, as long as the aggregate state stays the same, free entry of the firms will ensure the same equilibrium level of $v / u$ through variations in $v^{20}$. Then $v / u$ becomes a sufficient statistic that determines vacant firms' problem. Hence, fluctuations in aggregate productivity is almost perfectly correlated with variations in $v / u$. In this case, market tightness, $v / u$, is an increasing function of $z$.

In order to understand the counterfactually positive correlation, consider staying in the same aggregate state for a few periods. Since $z$ is constant over periods, there will be no discrete changes in the profitability of an ongoing match. In other words, separations do not fluctuate a lot due to changes in $\bar{\gamma}(z)$. Thus, with the same level of $v / u$, unemployment will start shrinking over this episode. But, a constant $v / u$ implies that $v$ should also decline over the same episode. Thus, there will be a positive correlation between unemployment and vacancies over this particular episode. This seems to be a common feature of the standard model too. So, why do I get positive correlation here instead of the negative correlation implied by the standard model (with only exogenous separations ) ? The answer is intimately related to the behavior of separations. The absence of endogenous separations forces the economy to adjust to new aggregate shocks via changing the hiring behavior. If this is the only channel, then changes in unemployment is induced only through the job finding probability, $f(v / u)$. However, with endogenous separations due to low productivity, unemployment is also affected by countercyclical separations. This dampens the magnitude of variations required in $v$ in response to negative productivity shock. Since such a negative shock induces a sharp decline in $u$, the lower equilibrium value for $v / u$ could be attained even with small changes (and in Table 4 with large declines) in $v^{21}$.

On the other hand, the model with on-the-job search implies a much more realistic picture in this regard. In contrast to the benchmark model, the relevant equilibrium object is not $v / u$ but only $v$. Hence, aggregate productivity fluctuations are accommodated through changes

\footnotetext{
${ }^{20}$ This is a fairly standard observation made about the labor market search and matching models.

${ }^{21}$ Shimer (2005a) considers separation shocks as a possible driving force for unemployment fluctuations and discusses the point made here further.
} 
in the number of vacancies posted. But as argued in the rest of the discussion here, firms' incentive to create vacancies respond to the behavior of expected job-to-job transitions. This is the channel which reverse the counterfactual implications of the benchmark model.

How does job-to-job transition create amplification and help to reconcile endogenous separations with the Beveridge curve? The answer to this question lies at the heart of the model. First, it is important to understand how the match quality distribution evolves in response to aggregate productivity shocks. In order to illustrate this, it might be useful to analyze what match quality distributions would look like in steady states with different productivity levels. These two different match quality distributions are shown in Figure (7). It is clear from the figure that, in the high productivity steady state there are some employed workers in low quality matches, which would have been unprofitable otherwise. It also happens to be the case that, since employment is higher in high productivity steady state, there are uniformly more workers employed in each match quality level. Because, workers are better of by switching to new jobs with higher quality, the odds of quitting and changing a job would be higher in the high aggregate productivity state. This is crucial for the firms that are considering to post vacancies. Remember that one critical object in the model was the value for $\mu$, which summarized this probability. Two distributions pictured in Figure (7) clearly show why one should expect more workers to be willing to accept job offers from vacancies. Hence, vacant firms might expect to meet with workers that are more willing to change jobs and accept their offers in expansions.

In the standard search model, when firms intend to create vacancies due to high aggregate productivity, unemployment pool starts to shrink. Since new matches are formed only between vacancies and unemployed workers, as the high productivity prevails, firms loose incentive to create any more vacancies due to smaller pool of potential matches. Here, however, high productivity state serves as a good opportunity for workers to reallocate themselves for better quality matches. This improved reallocation across matches also gives further incentive to firms to create vacancies when aggregate productivity is high. Thus, the model implies a significantly procyclical labor market reallocation through procyclical job-to-job transitions. 
This model's implications for labor market flows are also instructive in this regard. First of all, by having the possibility of job-to-job transitions, the model has richer implications than the standard model. As Table 4 indicates, $e$-e flows are significantly procyclical and as variable as $u$-e flows. On the other hand, the flows from employment to unemployment is countercyclical as expected but has very large variation. The cyclicality of job-to-job transitions is in line with quits (Nagypal 2004a). However, we need to be cautious when interpreting u-e flows. In theory, these separations happen with mutual consent, so it is neither layoff nor quit. If both $e-u$ and $e$-e flows are considered to be "separations", the enormous volatility in $e-u$ does not carry over to all separations. This is due to the negative relationship between both flows constituting "separation," i.e the procyclicality of $e$-e dampens the effect of $e-u$.

\section{Conclusion}

The Mortensen-Pissarides labor market search model has been recently criticized because of the model's quantitative implications for business cycles. In particular, researchers have pointed out the discrepancy between the implied level of variation in unemployment, vacancies and market tightness and the observed variation in these variables in the United States. This paper extends the baseline labor market search model to include on-the-job search and match specific heterogeneity to generate the missing amplification. The mechanism works through the effects of aggregate productivity shocks on the entire employment distribution.

There is incomplete information about the quality of the employee-firm match which provides persistence in employment relationships and the rationale for on-the-job search. Amplification arises because productivity changes not only affect firms' probability of contacting unemployed workers but also of contacting already employed workers. Since the measure of workers in low quality matches is greater, this probability is higher during expansions. This introduces strongly procyclical labor market reallocation through procyclical job-to-job transitions, which has been a generally ignored feature in the literature. Hence, the model provides a possible channel which does not require changing the wage determination process or the information structure to a large extent to create more variation. In particular, simulations with 
a plausible forcing process show that the standard deviations for unemployment, vacancies and vacancy-unemployment ratio (market tightness) match the U.S. data. The model also reconciles the presence of endogenous separation with the negative correlation of unemployment and vacancies over business cycle frequencies.

This paper also has a methodological contribution. On-the-job search with match heterogeneity requires to take the entire employment distribution into account as part of the state space. It is well known in the literature that this complicates the numerical solution of the equilibrium. I adapt the algorithm used by Krusell and Smith (1998) to the problem described in this paper. The computational exercise suggests that approximating the worker's acceptance probability of a firm's job offer suffices to characterize the equilibrium. Other studies that have modeled on-the-job search either assumed simplifying assumptions to get rid of the endogenous effects of heterogeneity or simply restricted the analysis to non-stochastic equilibrium.

Several possible variations of the model has been ignored in this paper. One key feature that should be considered is the effect of strategic bargaining at the wage determination stage. Incorporating such an additional feature might be a natural extension of the model to get wage rigidity and therefore might provide a comparison to the mechanism advocated here. I have also focused on the mechanism itself without much discussion on the implied magnitudes of the flows. This is mostly the case, because the underlying calibration of the model does not target job-to-job flow statistics from recent studies. These possible extensions are left for future research. 


\section{. Appendix}

\section{A Standard Mortensen-Pissarides Model}

In order to facilitate comparison the notation for describing the standard Mortensen-Pissarides model will be similar to the notation used in the model presented in section 4, whenever possible.

There is a continuum of risk neutral workers and employers who discount the future at the rate $\beta \in(0,1)$. The measure of workers is normalized to 1 and they are either unemployed looking for a job or employed and producing $z_{t}>0$ each period. All matches are identical. Match output, $z_{t}$, is stochastic and governed by a Markov process, $\Psi\left(z_{t+1} \mid z_{t}\right)$. There is no onthe-job search. Hence, only unemployed workers are searching for a job. Active firms could be either producing by employing a worker, or waiting for a possible match after posting a vacancy. There is free entry of firms which guarantees that as long as the value of posting a vacancy is positive, there will be active firms posting vacancies. Posting a vacacny costs $c>0$ per period and enables vacant firms to meet an unemployed worker through a matching function, $M\left(v_{t}, u_{t}\right)$, where $v_{t}$ is the aggregate number of vacancies and $u_{t}$ is the aggregate number of unemployed workers. $M(v, u)$ is constant returns to scale, which implies the following probabilities of finding a job (for unemployed workers) and filling a vacancy (for vacant positions).

$$
f\left(\theta_{t}\right)=M\left(v_{t}, u_{t}\right) / u_{t} \text { and } h\left(\theta_{t}\right)=M\left(v_{t}, u_{t}\right) / v_{t} \text { where } M\left(v_{t}, u_{t}\right)=M u_{t}^{1-\eta} v_{t}^{\eta}
$$

Here $\theta_{t}=v_{t} / u_{t}$ is usually referred to as market tightness. When unemployed, workers consume $b>0$. Continuing matches are subject to exogenous destruction with probability $\lambda$ each period. Wage, $w\left(z_{t}\right)$, is determined each period via Nash bargaining between worker and firm taking the threat points as value of unemployment and value of being a vacant job respectively. Let the value of being unemployed be $V_{u}\left(z_{t}\right)$ and the value of a vacancy be $J_{u}\left(z_{t}\right)$. Similarly, the value of being employed for a worker and the value of being in a match for a firm are denoted by $V_{e}(z)$ and $J_{e}(z)$ respectively. These value functions are summarized in four 
Bellman equations:

$$
\begin{gathered}
V_{u}(z)=b+\beta E_{z^{\prime} \mid z}\left\{f(\theta(z)) V_{e}\left(z^{\prime}\right)+(1-f(\theta(z))) V_{u}\left(z^{\prime}\right)\right\} \\
V_{e}(z)=w(z)+\beta E_{z^{\prime} \mid z}\left\{(1-\lambda) V_{e}\left(z^{\prime}\right)+\lambda V_{u}\left(z^{\prime}\right)\right\} \\
J_{u}(z)=-c+\beta E_{z^{\prime} \mid z}\left\{h(\theta(z)) J_{e}\left(z^{\prime}\right)+(1-h(\theta(z))) J_{u}\left(z^{\prime}\right)\right\} \\
J_{e}(z)=z-w(z)+\beta E_{z^{\prime} \mid z}\left\{(1-\lambda) J_{e}\left(z^{\prime}\right)+\lambda J_{u}\left(z^{\prime}\right)\right\}
\end{gathered}
$$

where time subscripts are dropped for convenience.

Consequently, the equilibrium of this economy satisfies the following conditions:

1. (Optimization) Given, $\theta(z)$ and $w(z)$, value functions $V_{u}(z), V_{e}(z), J_{u}(z)$ and $J_{e}(z)$ satisfy (22) - (25).

2. (Free entry) Given $\theta(z)$ and $w(z)$ a firm is willing to post a vacany as long as $J_{u}(z)>0$. Therefore in equilibrium, due to free entry $J_{u}(z)=0$.

3. (Nash Bargaining) $V_{e}(z)-V_{u}(z)=\phi\left[V_{e}(z)-V_{u}(z)+J_{e}(z)-J_{u}(z)\right]$, where $\phi \in[0,1]$ is the worker's bargaining strength.

4. (Equation of motion for unemployment) Given an initial unemployment $u_{0}$ decisions should be consistent with the evolution of unemployment.

$$
u^{\prime}=(1-u) \lambda+u(1-f(\theta))
$$

The simulations in Table 2 use the following calibration. 


\begin{tabular}{lll}
\hline \hline \multicolumn{3}{c}{ Table A. Calibration for MP Model } \\
\hline \hline Parameter & Value & \\
\hline$\beta$ & 0.9967 & $4 \%$ interest \\
$\phi$ & 0.36 & Shimer $(2005)$ \\
$\eta$ & 0.36 & Shimer $(2005)$ \\
$y^{l}$ & 1 & Normalization \\
$z^{h}$ & 1.0259 & U.S. Avg. \\
$z^{l}$ & 0.9748 & Output p/w \\
$z^{s s}$ & 1 & Normalization \\
$\lambda$ & 0.0339 & Shimer $(2005)$ \\
$b$ & 0.4 & Shimer $(2005)$ \\
$c$ & 0.24 & Match $u^{s s}=0.0568$ \\
$M$ & 0.35 & Match $f\left(\theta^{s s}\right)=0.45$ \\
\hline
\end{tabular}

\section{B Surplus Function and Equilibrium Value of Vacancy}

First, write down the values of $J_{e}(\gamma, z, n)-J_{u}(z, n)$ and $V_{e}(\gamma, z, n)-V_{u}(z, n)$ by subtracting (9) and (7) from (10) and (8) respectively. 


$$
\begin{aligned}
& V_{e}(\gamma, z, n)-V_{u}(z, n)= \\
& \max \left\{\begin{array}{c}
w(\gamma, z, \mu) \\
+\beta(1-\lambda)(1-f(v)) E_{z^{\prime} \mid z}\left[\begin{array}{c}
\alpha(\gamma)\left(V_{e}\left(\gamma^{h}, z^{\prime}, \mu^{\prime}\right)-V_{u}\left(z^{\prime}, \mu^{\prime}\right)\right) \\
+(1-\alpha(\gamma))\left(V_{e}\left(\gamma^{l}, z^{\prime}, \mu^{\prime}\right)-V_{u}\left(z^{\prime}, \mu^{\prime}\right)\right)
\end{array}\right] \\
+\beta(1-\lambda) f(v) \alpha(\gamma) E_{z^{\prime} \mid z}\left[\begin{array}{c}
\Gamma\left(\gamma^{h}\right)\left(V_{e}\left(\gamma^{h}, z^{\prime}, \mu^{\prime}\right)-V_{u}\left(z^{\prime}, \mu^{\prime}\right)\right) \\
+\int_{\gamma^{h}}\left(V_{e}\left(\gamma^{\prime}, z^{\prime}, \mu^{\prime}\right)-V_{u}\left(z^{\prime}, \mu^{\prime}\right)\right) d \Gamma\left(\gamma^{\prime}\right)
\end{array}\right] \\
{\left[\begin{array}{c}
\Gamma\left(\gamma^{l}\right)\left(V_{e}\left(\gamma^{l}, z^{\prime}, \mu^{\prime}\right)-V_{u}\left(z^{\prime}, \mu^{\prime}\right)\right) \\
+\int_{\gamma^{l}}\left(V_{e}\left(\gamma^{\prime}, z^{\prime}, \mu^{\prime}\right)-V_{u}\left(z^{\prime}, \mu^{\prime}\right)\right) d \Gamma\left(\gamma^{\prime}\right)
\end{array}\right]} \\
-V_{u}(z, \mu)+\beta \lambda E_{z^{\prime} \mid z} V_{u}\left(z^{\prime}, \mu^{\prime}\right)+\beta(1-\lambda)(1-f(v)) E_{z^{\prime} \mid z} V_{u}\left(z^{\prime}, \mu^{\prime}\right) \\
+\beta(1-\lambda) f(v) \alpha(\gamma) E_{z^{\prime} \mid z} V_{u}\left(z^{\prime}, \mu^{\prime}\right) \\
+\beta(1-\lambda) f(v)(1-\alpha(\gamma)) E_{z^{\prime} \mid z} V_{u}\left(z^{\prime}, \mu^{\prime}\right), 0
\end{array}\right\}
\end{aligned}
$$

$$
\left.\begin{array}{l}
J_{e}(\gamma, z, \mu)-J_{u}(z, \mu)= \\
\max \left\{\begin{array}{c}
z\left(\alpha(\gamma) y^{h}+(1-\alpha(\gamma)) y^{l}\right)-w(\gamma, z, n) \\
+\beta(1-\lambda)(1-f(v)) E_{z^{\prime} \mid z}\left[\begin{array}{c}
\alpha(\gamma)\left(J_{e}\left(\gamma^{h}, z^{\prime}, n^{\prime}\right)-J_{u}\left(z^{\prime}, n^{\prime}\right)\right) \\
+(1-\alpha(\gamma))\left(J_{e}\left(\gamma^{l}, z^{\prime}, n^{\prime}\right)-J_{u}\left(z^{\prime}, n^{\prime}\right)\right)
\end{array}\right] \\
+\beta(1-\lambda) f(v) \alpha(\gamma) E_{z^{\prime} \mid z}\left[\begin{array}{c}
\Gamma\left(\gamma^{h}\right)\left(J_{e}\left(\gamma^{h}, z^{\prime}, n^{\prime}\right)-J_{u}\left(z^{\prime}, n^{\prime}\right)\right) \\
+\left(1-\Gamma\left(\gamma^{h}\right)\right) J_{u}\left(z^{\prime}, n^{\prime}\right)
\end{array}\right] \\
+\beta(1-\lambda) f(v)(1-\alpha(\gamma)) E_{z^{\prime} \mid z}\left[\begin{array}{c}
\Gamma\left(\gamma^{l}\right)\left(J_{e}\left(\gamma^{l}, z^{\prime}, n^{\prime}\right)-J_{u}\left(z^{\prime}, n^{\prime}\right)\right) \\
+\left(1-\Gamma\left(\gamma^{l}\right)\right) J_{u}\left(z^{\prime}, n^{\prime}\right)
\end{array}\right]-J_{u}(z, n) \\
+\beta \lambda E_{z^{\prime} \mid z} J_{u}\left(z^{\prime}, n^{\prime}\right)+\beta(1-\lambda)(1-f(v)) E_{z^{\prime} \mid z} J_{u}\left(z^{\prime}, n^{\prime}\right) \\
+\beta(1-\lambda) f(v) \alpha(\gamma) E_{z^{\prime} \mid z} \Gamma\left(\gamma^{h}\right) J_{u}\left(z^{\prime}, n^{\prime}\right) \\
+\beta(1-\lambda) f(v)(1-\alpha(\gamma)) E_{z^{\prime} \mid z} \Gamma\left(\gamma^{l}\right) J_{u}\left(z^{\prime}, n^{\prime}\right), 0
\end{array}\right.
\end{array}\right\}
$$

Imposing the free entry condition, $J_{u}(z, n)=0 \forall z, n$, and some simplification, yield the 
following two equations.

$$
\begin{aligned}
& V_{e}(\gamma, z, n)-V_{u}(z, n)= \\
& \max \left\{\begin{array}{c}
w(\gamma, z, n) \\
+\beta(1-\lambda)(1-f(v)) E_{z^{\prime} \mid z}\left[\begin{array}{c}
\alpha(\gamma)\left(V_{e}\left(\gamma^{h}, z^{\prime}, n^{\prime}\right)-V_{u}\left(z^{\prime}, n^{\prime}\right)\right) \\
+(1-\alpha(\gamma))\left(V_{e}\left(\gamma^{l}, z^{\prime}, n^{\prime}\right)-V_{u}\left(z^{\prime}, n^{\prime}\right)\right)
\end{array}\right] \\
+\beta(1-\lambda) f(v) \alpha(\gamma) E_{z^{\prime} \mid z}\left[\begin{array}{c}
\Gamma\left(\gamma^{h}\right)\left(V_{e}\left(\gamma^{h}, z^{\prime}, n^{\prime}\right)-V_{u}\left(z^{\prime}, n^{\prime}\right)\right) \\
+\int_{\gamma^{h}}\left(V_{e}\left(\gamma^{\prime}, z^{\prime}, n^{\prime}\right)-V_{u}\left(z^{\prime}, n^{\prime}\right)\right) d \Gamma\left(\gamma^{\prime}\right)
\end{array}\right] \\
{\left[\begin{array}{c}
\Gamma\left(\gamma^{l}\right)\left(V_{e}\left(\gamma^{l}, z^{\prime}, n^{\prime}\right)-V_{u}\left(z^{\prime}, n^{\prime}\right)\right) \\
+\int_{\gamma^{l}}\left(V_{e}\left(\gamma^{\prime}, z^{\prime}, n^{\prime}\right)-V_{u}\left(z^{\prime}, n^{\prime}\right)\right) d \Gamma\left(\gamma^{\prime}\right)
\end{array}\right]} \\
-\beta(1-\lambda) f(v)(1-\alpha(\gamma)) E_{z^{\prime} \mid z}\left[\begin{array}{c} 
\\
-\beta E_{z^{\prime} \mid z} V_{u}\left(z^{\prime}, n^{\prime}\right), 0
\end{array}\right.
\end{array}\right\}
\end{aligned}
$$

$$
\begin{aligned}
& J_{e}(\gamma, z, n)-J_{u}(z, n)=
\end{aligned}
$$

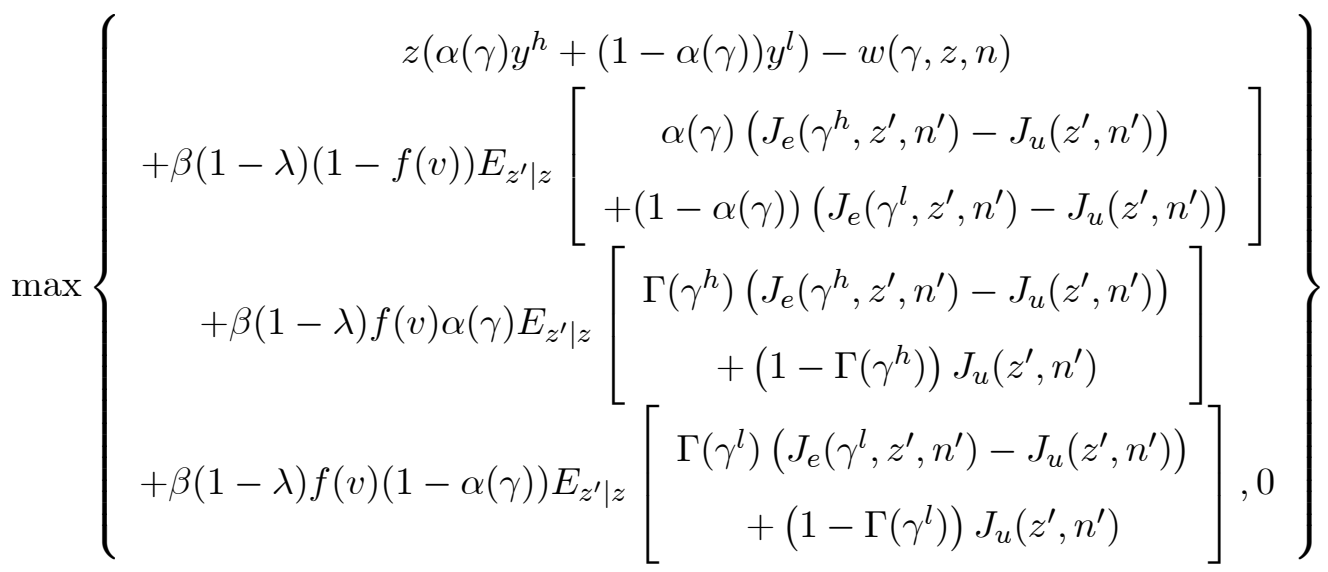

Let $S(\gamma, z, n)=J_{e}(\gamma, z, n)-J_{u}(z, n)+V_{e}(\gamma, z, n)-V_{u}(z, n)$ denote the match surplus. Adding (29) and (30) provides the following expression for the match surplus. 


$$
S(\gamma, z, n)=\max \left\{\begin{array}{c}
z\left(\alpha(\gamma) y^{h}+(1-\alpha(\gamma)) y^{l}\right) \\
+\beta(1-\lambda)(1-f(v)) E_{z^{\prime} \mid z}\left[\alpha(\gamma) S\left(\gamma^{h}, z^{\prime}, n^{\prime}\right)+(1-\alpha(\gamma)) S\left(\gamma^{l}, z^{\prime}, n^{\prime}\right)\right] \\
+\beta(1-\lambda) f(v) \alpha(\gamma) E_{z^{\prime} \mid z}\left[\begin{array}{c}
\Gamma\left(\gamma^{h}\right) S\left(\gamma^{h}, z^{\prime}, n^{\prime}\right) \\
+\int_{\gamma^{h}}\left(V_{e}\left(\gamma^{\prime}, z^{\prime}, n^{\prime}\right)-V_{u}\left(z^{\prime}, n^{\prime}\right)\right) d \Gamma\left(\gamma^{\prime}\right)
\end{array}\right] \\
+\beta(1-\lambda) f(v)(1-\alpha(\gamma)) E_{z^{\prime} \mid z}\left[\begin{array}{c}
\Gamma\left(\gamma^{l}\right) S\left(\gamma^{l}, z^{\prime}, n^{\prime}\right) \\
+\int_{\gamma^{l}}\left(V_{e}\left(\gamma^{\prime}, z^{\prime}, n^{\prime}\right)-V_{u}\left(z^{\prime}, n^{\prime}\right)\right) d \Gamma\left(\gamma^{\prime}\right)
\end{array}\right] \\
-V_{u}(z, n)+\beta E_{z^{\prime} \mid z} V_{u}\left(z^{\prime}, n^{\prime}\right), 0
\end{array}\right\}
$$

The surplus sharing rule implies that $V_{e}(\gamma, z, n)-V_{u}(z, n)=\phi S(\gamma, z, n)$ for all $\gamma, z, n$. This leads to following equalities:

$$
\begin{gathered}
\int_{\gamma^{h}}\left(V_{e}\left(\gamma^{\prime}, z^{\prime}, n^{\prime}\right)-V_{u}\left(z^{\prime}, n^{\prime}\right)\right) d \Gamma\left(\gamma^{\prime}\right)=\phi \int_{\gamma^{h}} S\left(\gamma^{\prime}, z^{\prime}, n^{\prime}\right) d \Gamma\left(\gamma^{\prime}\right) \\
\int_{\gamma^{l}}\left(V_{e}\left(\gamma^{\prime}, z^{\prime}, n^{\prime}\right)-V_{u}\left(z^{\prime}, n^{\prime}\right)\right) d \Gamma\left(\gamma^{\prime}\right)=\phi \int_{\gamma^{l}} S\left(\gamma^{\prime}, z^{\prime}, n^{\prime}\right) d \Gamma\left(\gamma^{\prime}\right)
\end{gathered}
$$

Then the surplus function reduces to

$$
S(\gamma, z, n)=\max \left\{\begin{array}{c}
z\left(\alpha(\gamma) y^{h}+(1-\alpha(\gamma)) y^{l}\right) \\
+\beta(1-\lambda)(1-f(v)) E_{z^{\prime} \mid z}\left[\alpha(\gamma) S\left(\gamma^{h}, z^{\prime}, n^{\prime}\right)+(1-\alpha(\gamma)) S\left(\gamma^{l}, z^{\prime}, n^{\prime}\right)\right] \\
+\beta(1-\lambda) f(v) \alpha(\gamma) E_{z^{\prime} \mid z}\left[\Gamma\left(\gamma^{h}\right) S\left(\gamma^{h}, z^{\prime}, n^{\prime}\right)+\phi \int_{\gamma^{h}} S\left(\gamma^{\prime}, z^{\prime}, n^{\prime}\right) d \Gamma\left(\gamma^{\prime}\right)\right] \\
+\beta(1-\lambda) f(v)(1-\alpha(\gamma)) E_{z^{\prime} \mid z}\left[\Gamma\left(\gamma^{l}\right) S\left(\gamma^{l}, z^{\prime}, n^{\prime}\right)+\phi \int_{\gamma^{l}} S\left(\gamma^{\prime}, z^{\prime}, n^{\prime}\right) d \Gamma\left(\gamma^{\prime}\right)\right] \\
-V_{u}(z, n)+\beta E_{z^{\prime} \mid z} V_{u}\left(z^{\prime}, n^{\prime}\right), 0
\end{array}\right\}
$$

Now I need to use (7) to pin down the value of $-V_{u}(z, n)+\beta E_{z^{\prime} \mid z} V_{u}\left(z^{\prime}, n^{\prime}\right)$ in terms of surplus function. It is possible by substituting $V_{u}(z, n)+\phi S(\gamma, z, n)$ for $V_{e}(\gamma, z, n)$, using the surplus sharing rule. 


$$
V_{u}(z, n)=b+\beta E_{z^{\prime} \mid z}\left\{f(v) \int\left[V_{u}\left(z^{\prime}, n^{\prime}\right)+\phi S\left(\gamma^{\prime}, z^{\prime}, n^{\prime}\right)\right] d \Gamma\left(\gamma^{\prime}\right)+(1-f(v)) V_{u}\left(z^{\prime}, n^{\prime}\right)\right\}
$$

And further simplification of (32) yields the desired expression.

$$
V_{u}(z, n)-\beta E_{z^{\prime} \mid z} V_{u}\left(z^{\prime}, n^{\prime}\right)=b+\beta E_{z^{\prime} \mid z} f(v) \phi \int S\left(\gamma^{\prime}, z^{\prime}, n^{\prime}\right) d \Gamma\left(\gamma^{\prime}\right)
$$

Substituting (34) in (32) reduces (32) to a recursive functional equation in $S(\gamma, z, n)$.

$$
S(\gamma, z, n)=\max \left\{\begin{array}{c}
z\left(\alpha(\gamma) y^{h}+(1-\alpha(\gamma)) y^{l}\right)-b \\
+\beta(1-\lambda)(1-f(v)) E_{z^{\prime} \mid z}\left[\alpha(\gamma) S\left(\gamma^{h}, z^{\prime}, n^{\prime}\right)+(1-\alpha(\gamma)) S\left(\gamma^{l}, z^{\prime}, n^{\prime}\right)\right] \\
+\beta(1-\lambda) f(v) \alpha(\gamma) E_{z^{\prime} \mid z}\left[\Gamma\left(\gamma^{h}\right) S\left(\gamma^{h}, z^{\prime}, n^{\prime}\right)+\phi \int_{\gamma^{h}} S\left(\gamma^{\prime}, z^{\prime}, n^{\prime}\right) d \Gamma\left(\gamma^{\prime}\right)\right] \\
+\beta(1-\lambda) f(v)(1-\alpha(\gamma)) E_{z^{\prime} \mid z}\left[\Gamma\left(\gamma^{l}\right) S\left(\gamma^{l}, z^{\prime}, n^{\prime}\right)+\phi \int_{\gamma^{l}} S\left(\gamma^{\prime}, z^{\prime}, n^{\prime}\right) d \Gamma\left(\gamma^{\prime}\right)\right] \\
-\beta E_{z^{\prime} \mid z} f(v) \phi \int S\left(\gamma^{\prime}, z^{\prime}, n^{\prime}\right) d \Gamma\left(\gamma^{\prime}\right), 0
\end{array}\right\}
$$

On the other hand, one can write down the equilibrium value of vacancy as a function of the surplus function. This follows from the definition of (9) and surplus sharing rule, $J_{e}(\gamma, z, n)-J_{u}(z, n)=(1-\phi) S(\gamma, z, n)$ for all $\gamma, z, n$. Using these two conditions I arrive at the following condition:

$$
J_{u}(z, n)=-c+\beta E_{z^{\prime} \mid z} J_{u}\left(z^{\prime}, n^{\prime}\right)+\beta h(v) \mu(1-\phi) E_{z^{\prime} \mid z} \int S\left(\gamma^{\prime}, z^{\prime}, n^{\prime}\right) d \Gamma\left(\gamma^{\prime}\right)
$$




\section{References}

[1] Andalfatto, D., 1996. "Business Cycles and Labor Market Search," American Economic Review, 86, 112-132.

[2] Barlevy, G., 2002. "The sullying Effect of Recessions," Review of Economic Studies, 69, 65-96.

[3] Cole, H. and R. Rogerson., 1999. "Can the Mortensen-Pissarides Matching model Match the Business Cycle Facts?" International Economic Review, 40, 933-959.

[4] Davis, S. and Haltiwanger, J., and Schuh, S., 1996. Job Creation and Destruction, MIT Press, Cambridge, MA.

[5] Fallick, B. and C. A. Fleischman., (2004). "Employer -to-Employer Flows in the U.S Labor Market: The Complete Picture of Gross Worker Flows," mimeo Federal Reserve Board.

[6] Fujita, S. and G. Ramey., (2005). "The Dynamic Beveridge Curve," Federal Reserve Bank of Philadelphia Working Paper No.05-22

[7] Hagedorn M. and I. Manovskii., (2005). "The Cyclical Behavior of Equilibrium Unemployment and Vacancies Revisited," mimeo, University of Pennsylvania.

[8] Hall, R.E., 2004. "The Amplification of Unemployment Fluctuations through SelfSelection," mimeo, Stanford University.

[9] Hall, R.E., 2005. "Employment Fluctuations with Equilibrium Wage Stickiness," American Economic Review, 95.1, 50-65.

[10] Jovanovic, B., 1979. "Job Matching and the Theory of Turnover," Journal of Political Economy, 87, 972-999.

[11] Kennan, J., 2004. "Private Information, Wage Bargaining and Employment Fluctuations," mimeo, University of Wisconsin-Madison.

[12] Krause, M. U. and T. A. Lubik, 2004. "On-the-Job Search and the Cyclical Dynamics of the Labor Market," mimeo, Tilburg University.

[13] Krusell, P. and A. Smith, 1998. "Income and Wealth Heterogeneity in the Macroeconomy," Journal of Political Economy, 106, 867-896.

[14] Merz, M., 1995. "Search in the Labor Market and the Real Business Cycle," Journal of Monetary Economics, 36, 269-300.

[15] Mortensen, D. and C. Pissarides, 1994. "Job Creation and Job Destruction in the Theory of Unemployment," Review of Economic Studies, 61, 397-415.

[16] Mortensen, D. and E Nagypal, 2005. "More on Unemployment and Vacancy Fluctuations," IZA Discussion Paper Series, No. 1765.

[17] Nagypal, E., 2004a. "Worker Reallocation over the Business Cycle: The Importance of Job-to-Job Transitions," mimeo, Northwestern University. 
[18] Nagypal, E., 2004b. "Learning-by-Doing Versus Learning About Match Quality: Can We Tell Them Apart?" mimeo, Northwestern University.

[19] Nagypal, E., 2005. "Amplification of Productivity Shocks: Why don't Vacancies Like to Hire the Unemployed?," mimeo, Northwestern University.

[20] Pissarides, C., 2000. Equilibrium Unemployment Theory, MIT Press, Cambridge, MA, second edn.

[21] Pries, M., 2004. "Persistence of Unemployment Fluctuations: A Model of Recurring Job Loss," Review of Economic Studies, 71, 193-215.

[22] Pries, M. and R. Rogerson, 2005. "Hiring Policies, Labor Market Institutions, and Labor Market Flows," Journal of Political Economy, 113, 811-839.

[23] Ramey, G. and J. Watson, 1997. "Contractual Fragility, Job Destruction and Business Cycles," Quarterly Journal of Economics, 112, 873-911.

[24] Shimer, R., 2003. "Dynamics in a Model of On-the-Job Search," mimeo, University of Chicago.

[25] Shimer, R., 2004. "The Consequences of Rigid Wages in Search Models," Journal of the European Economic Association (Papers and Proceedings), 2, 469-479.

[26] Shimer, R., 2005a. "The Cyclical Behavior of Unemployment and Vacancies: Evidence and Theory," American Economic Review, 95.1, 25-49.

[27] Shimer, R., 2005b. "The Cyclicality of Hires, Separations, and Job-to-Job Transitions," Federal Reserve Bank of St. Louis Review, 87.4, 493-507.

[28] Silva, J. I. and M. Toledo, 2005. "Labor Turnover Costs and the Cyclical Behavior of Vacancies and Unemployment," mimeo, Universidad Autonoma de Barcelona.

[29] Tauchen, G. 1986. "Finite State Markov-Chain Approximation to Univariate and Vector Autoregressions,' Economics Letters, 20, 177-181. 


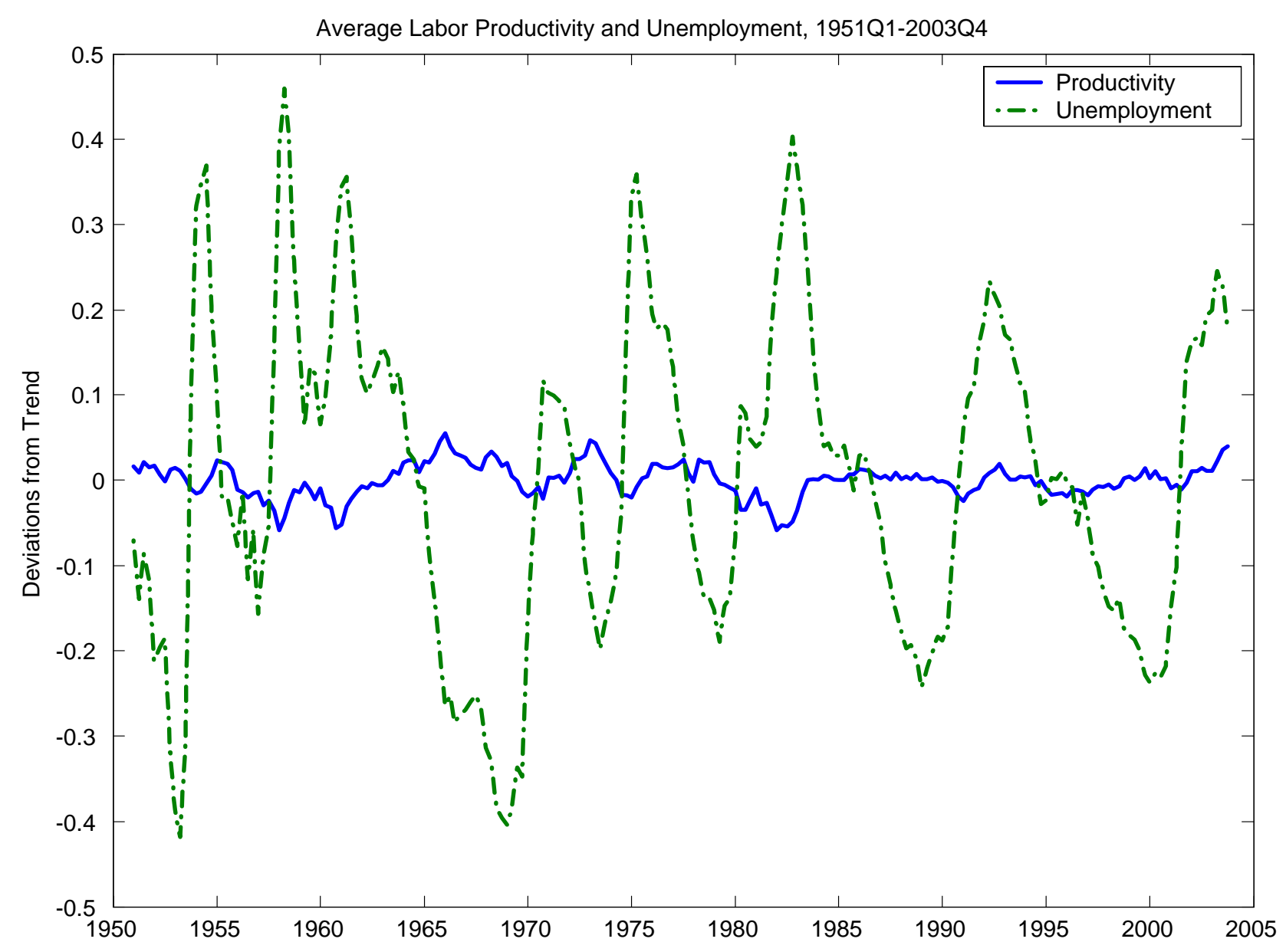

Figure 1: Unemployment is the quarterly average of the seasonally adjusted monthly series constructed by the BLS using the CPS data. Average labor productivity refers to real output per person in the non-farm business sector. This series is part of BLS's Major Sector Productivity and Costs program. Index is 100 for 1992. Both unemployment rate and average labor productivty are expressed in log deviations from an HP filter with a smoothing parameter 10^5. 


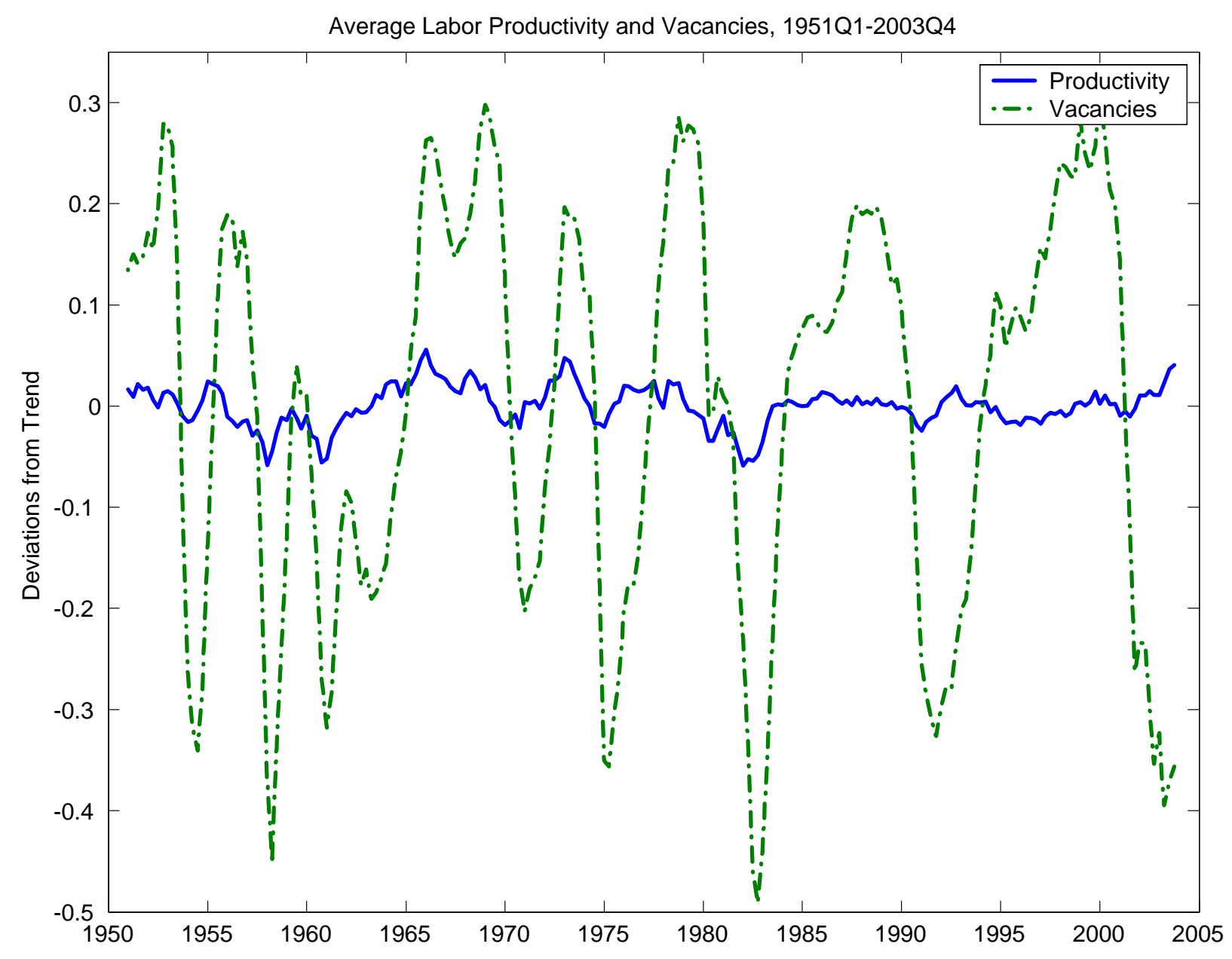

Figure 2: Vacancies are proxied by quarterly averages of seasonally adjusted monthly HelpWanted Advertising Index constructed by the Conference Board. Index is 100 for 1987. Average labor productivity refers to real output per person in the non-farm business sector. This series is part of BLS's Major Sector Productivity and Costs program. Index is 100 for 1992. Both vacancies and average labor productivty are expressed in log deviations from an HP filter with a smoothing parameter $10^{\wedge} 5$. 


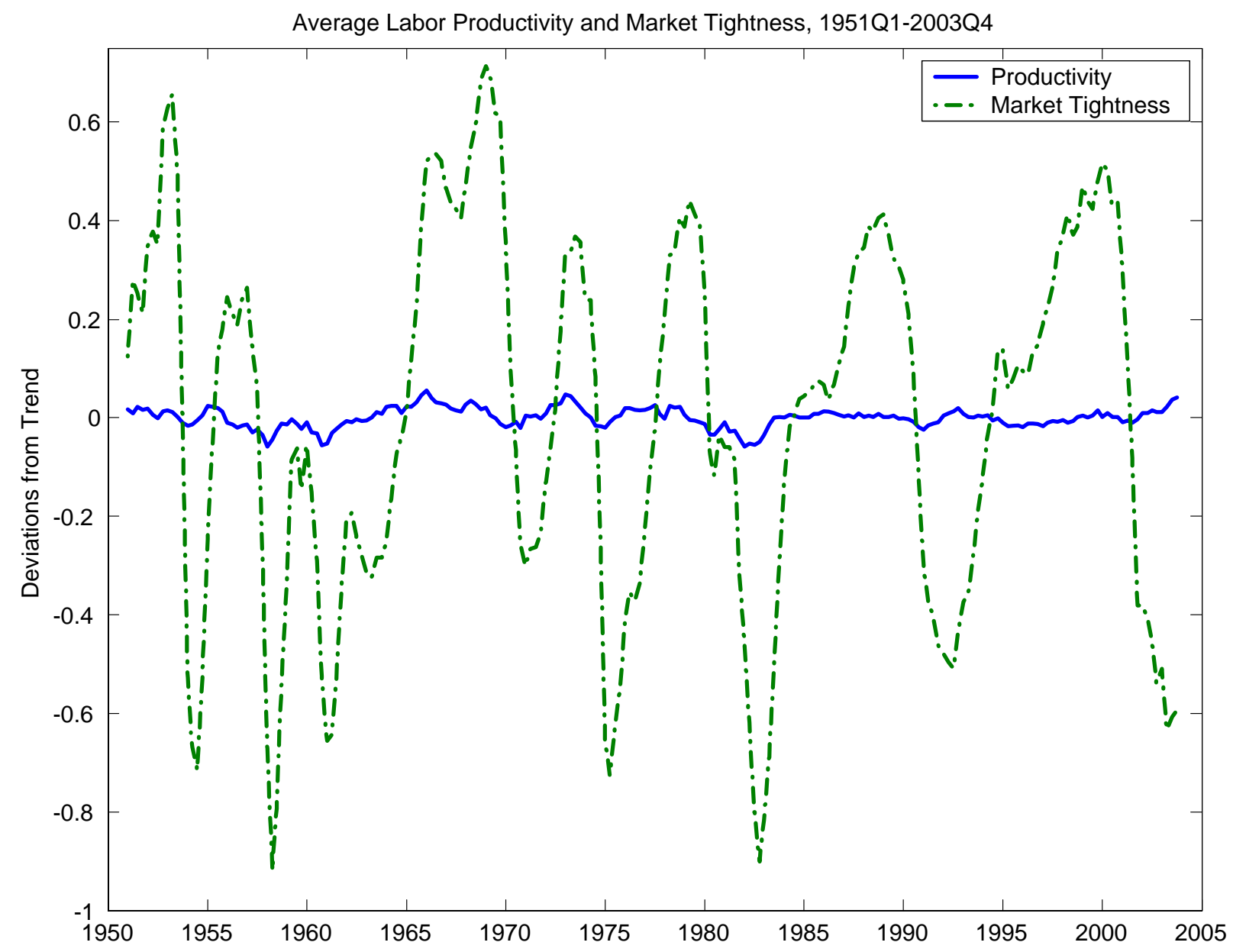

Figure 3: Market tightness is the ratio of vacancies to unemployment. Quarterly averages of the seasonally adjusted monthly series are reported. Average labor productivity refers to real output per person in the non-farm business sector. This series is part of BLS's Major Sector Productivity and Costs program. Index is 100 for 1992. Both market tightness and average labor productivty are expressed in log deviations from an HP filter with a smoothing parameter $10^{\wedge} 5$. 


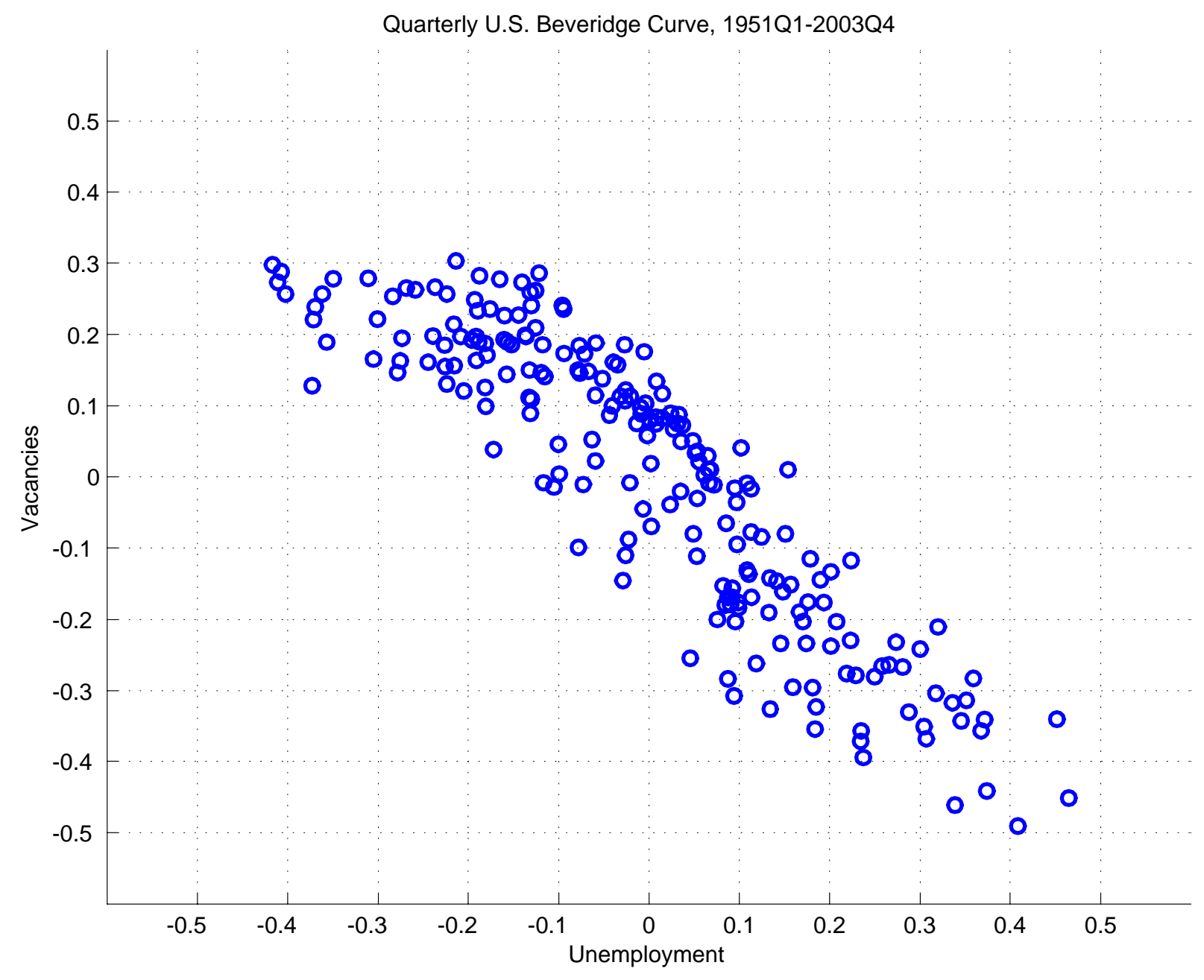

Figure 4: Vacancies are proxied by the quarterly averages of the seasonally adjusted monthly Help-Wanted Advertising Index constructed by the Conference Board. Index is 100 for 1987. Unemployment is the quarterly average of the seasonally adjusted monthly series constructed by the BLS using the CPS data. Both vacancies and unemployment are expressed in log deviations from an HP filter with a smoothing parameter $10^{\wedge} 5$. 


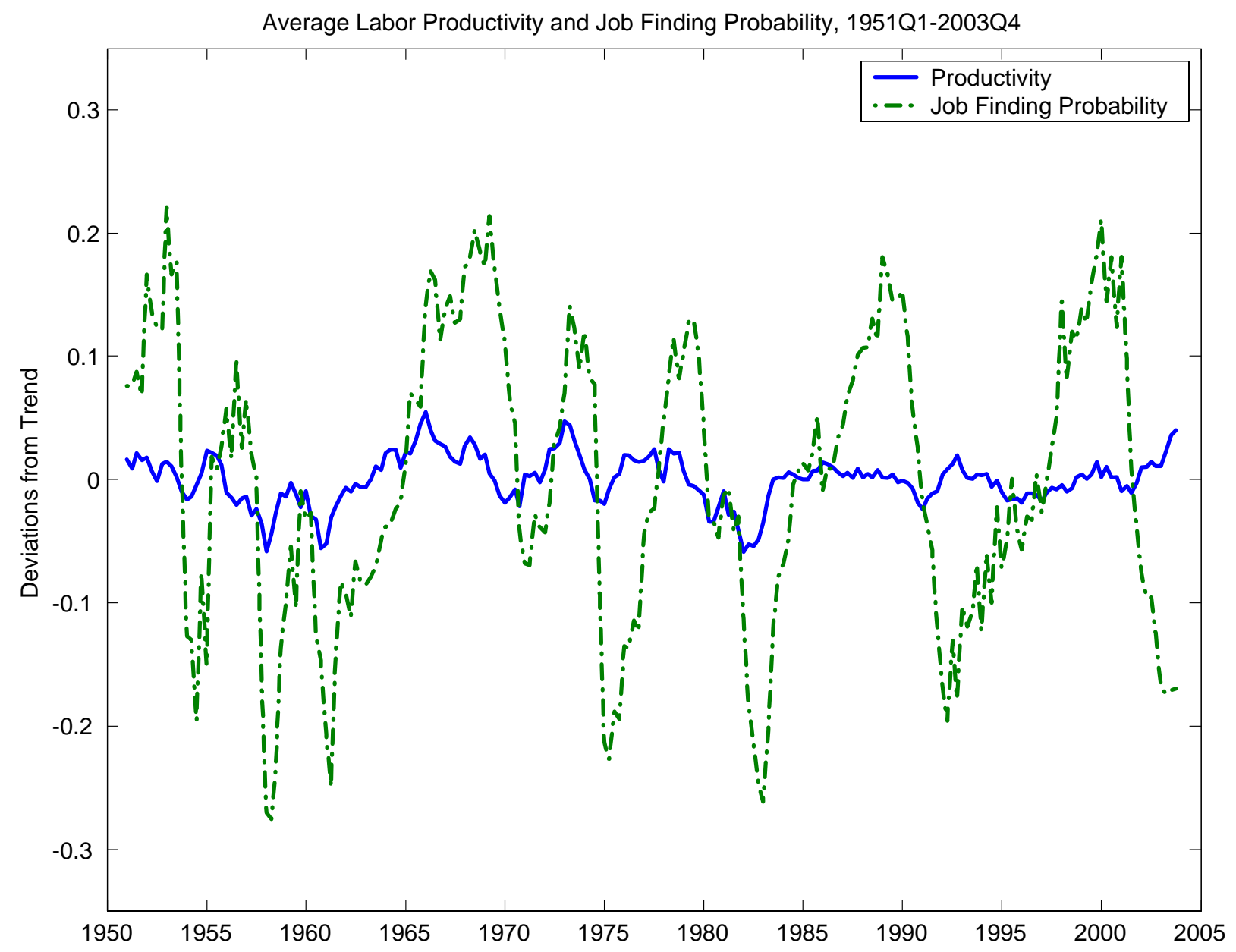

Figure 5: The Job finding Probability is constructed according to equation (1) in Section 2. All variables are expressed as log deviations from an HP trend with smoothing parameter $10^{\wedge} 5$. 


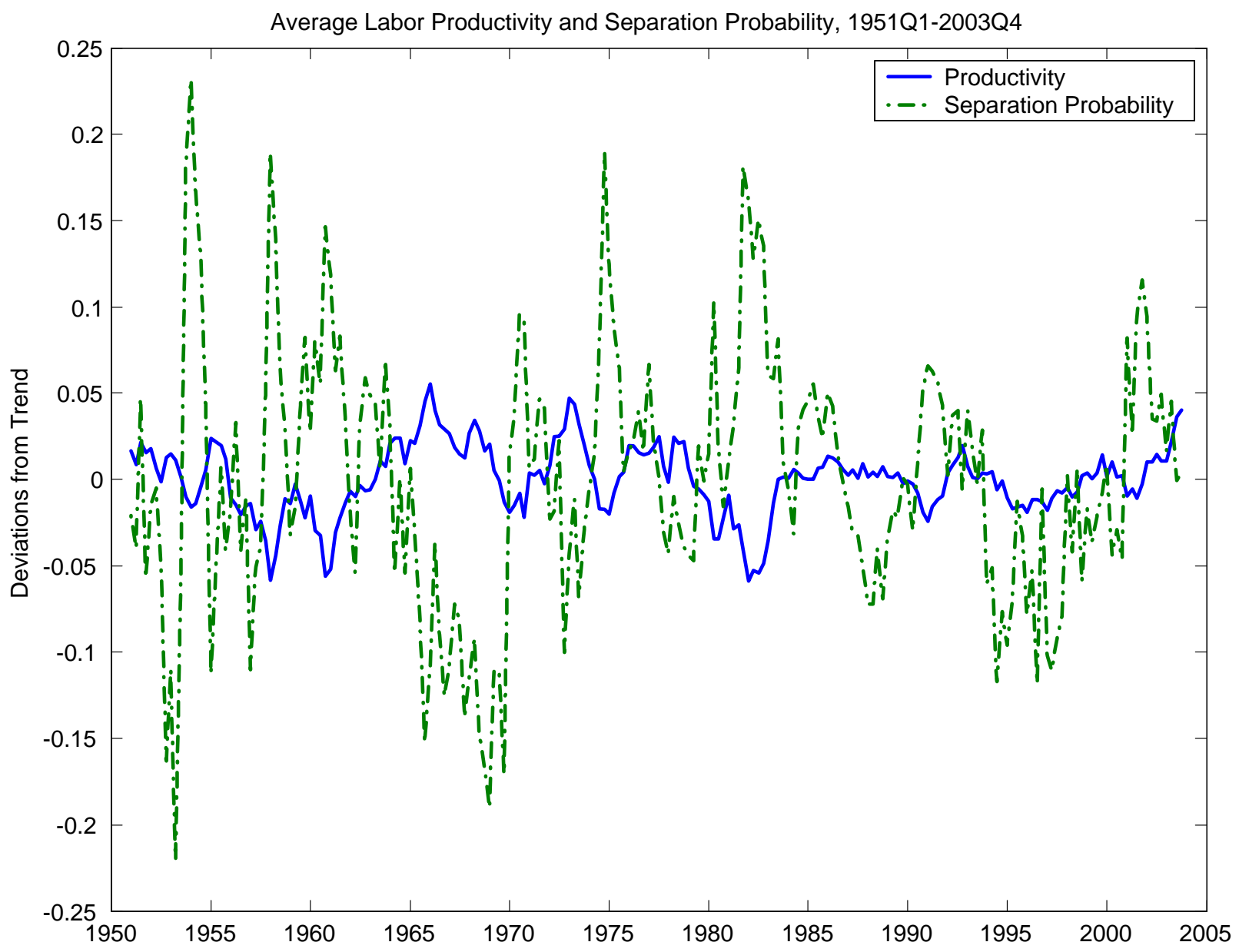

Figure 6: The Separation Probability is constructed according to equation (2) in Section 2. All variables are expressed as log deviations from an HP trend with smoothing parameter $10^{\wedge} 5$. 


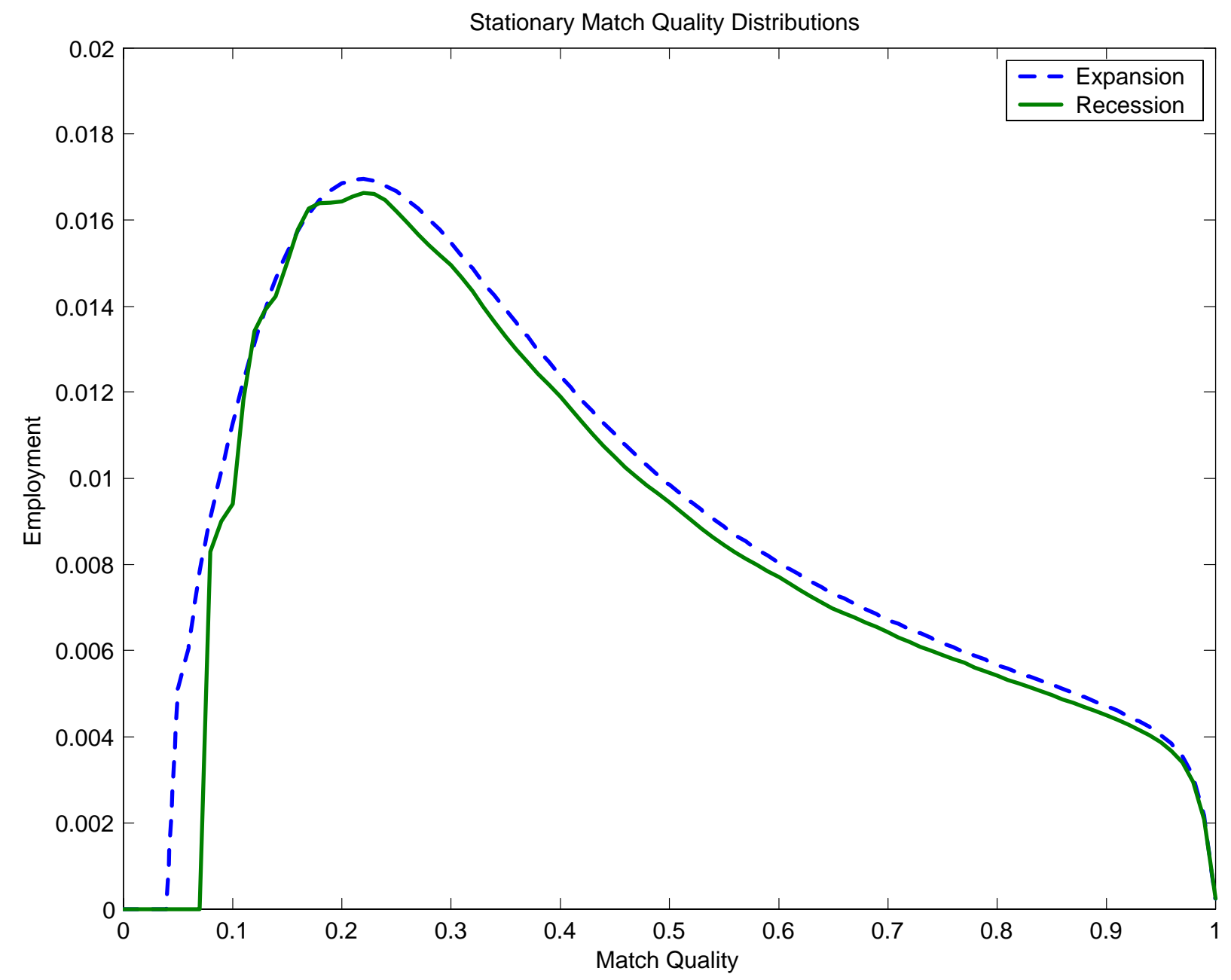

Figure 7: 